\title{
Status of Sorption Information Retrieval System
}

D. D. Hostetler

R. J. Serne

A. Brandstetter

September 1979

Prepared for the

Office of Nuclear Waste Isolation under its Contract with the

U.S. Department of Energy

Pacific Northwest Laboratory

Operated for the U.S. Department of Energy

by Battelle Memorial Institute 


\title{
NOTICE
}

This report was prepared as an account of work sponsored by the United States Government. Neither the United States nor the Department of Energy, nor-any of their employees, nor any of their contractors, subcontractors, or their employees, makes any warranty, express or implied, or assumes any legal liability or responsibility for the accuracy, completeness or usefulness of any information, apparatus, product or process disclosed, or represents that its use would not infringe privately owned rights.

The views, opinions and conclusions contained in this report are those of the contractor and do not necessarily represent those of the United States Government or the United States Department of Energy.

\author{
PACIFIC NORTHWEST LABORATORY \\ operated by \\ BATTELLE \\ for the \\ UNITED STATES DEPARTMENT OF ENERGY \\ Under Contract EY-76-C-06-1830
}

\author{
Printed in the United States of Americ \\ Available from \\ National Technical Information Service \\ United States Department of Commerce \\ 5285 Port Royal Road \\ Springfield, Virginia 22151
}

Price: Printed Copy 5 $\because$ Microfiche $\$ 3.00$

NTIS

* Pages Selling Price

\begin{tabular}{l|l}
$001-025$ & $\$ 4.00$ \\
$026-050$ & $\$ 4.50$ \\
$051-075$ & $\$ 5.25$ \\
$076-100$ & $\$ 6.00$ \\
$101-125$ & $\$ 6.50$ \\
$126-150$ & $\$ 7.25$ \\
$151-175$ & $\$ 8.00$ \\
$176-200$ & $\$ 9.00$ \\
$201-225$ & $\$ 9.25$ \\
$226-250$ & $\$ 9.50$ \\
$251-275$ & $\$ 10.75$ \\
$276-300$ & $\$ 11.00$
\end{tabular}




\section{1}

PNL -3139

Waste Isolation Safety Assessment Program

STATUS OF SORPTION INFORMATION RETRIEVAL SYSTEM

D. D. Hostetler

R. J. Serne

A. Brandstetter

September 1979

Prepared for the

Office of Nuclear Waste Isolation

Under Its Contract With the

U.S. Department of Energy

EY $-76-C-06-1830$

Pacific Northwest Laboratory

Richland, Washington 99352 


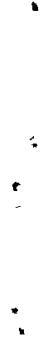




\section{SUMMARY}

A Sorption Information Retrieval System (SIRS) is being designed to provide an efficient, computerized, data base for information on radionuclide sorption in geologic media. The data bank will include Kd values for a large number of radionuclides occurring in radioactive wastes originating from the commercial nuclear power industry. Kd values determined to date span several groundwater compositions and a wide variety of rock types and minerals. The data system will not only include $K d$ values, but also background information on the experiments themselves. This will allow the potential user to retrieve not only the $K d$ values of interest but also sufficient information to evaluate the accuracy and usefulness of the data.

During FY-1979, the logic structure of the system was designed, the software programmed, the data categories selected, and the data format specified. About $40 \%$ of the approximately $5000 \mathrm{Kd}$ experiments performed by the Waste Isolation Safety Assessment Program (WISAP) and its subcontractors during FY-1977 and FY-1978 have been evaluated, coded and keypunched. Additional software improvements and system testing are needed before the system will be fully operationa1. A workshop requested by the Nuclear Energy Agency of the Organization for Economic Cooperation and Development was held to discusss potential international participation in the data system. 


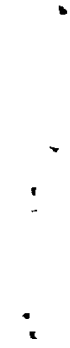




\section{CONTENTS}

SUMMARY

FIGURES

ACKNOWLEDGMENT .

INTRODUCTION

INFORMATION NEEDS

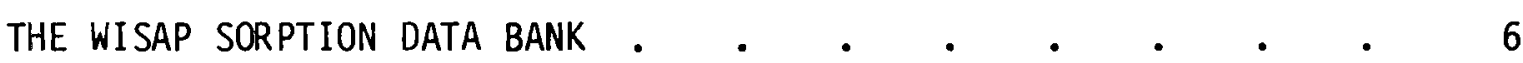

POTENTIAL USES •

SYSTEM DESCRIPTION

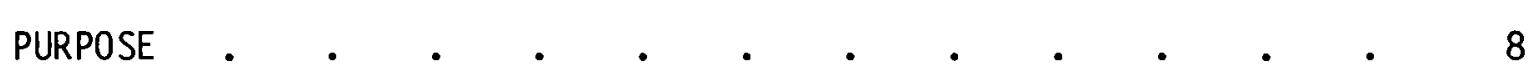

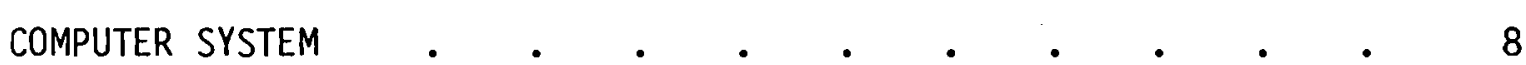

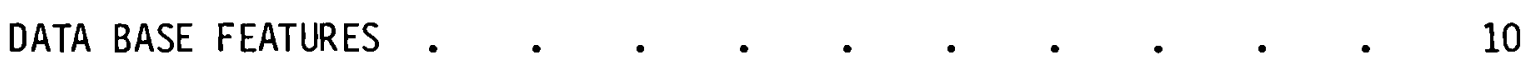

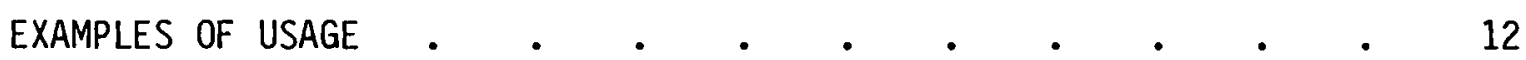

CURRENT STATUS •

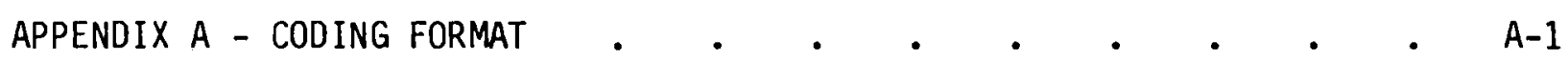

APPENDIX B - CODING TREES OR DATA CATEGORIES • • • • • . . $\quad$ B-1

APPENDIX C - DATA INPUT METHOD $•$ -

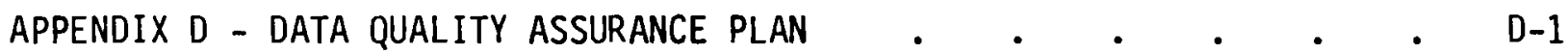




\section{FIGURES}

1 Radionuclide Interaction in Geologic Media . . . . . 3

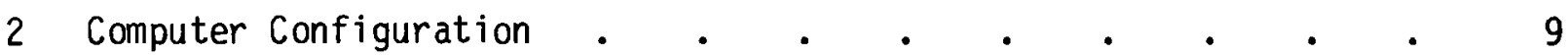

3 Experimental Details' Category Indices . . . . . . 11

4 Sorption Data Base Controller . . . . . . . . 13

5 Data Base Analyzer - Level 1 .

6 Data Base Analyzer - Level 2 . . . . . . . . . 16

7 Data Base Analyzer - Level 3 . . . . . . . . . 17

8 Data Base Analyzer - Level 4 . $\quad . \quad$. $\quad . \quad$. . . . 18

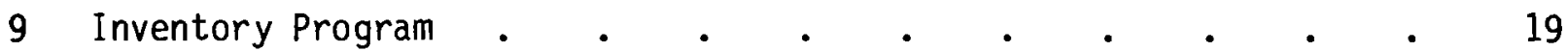




\section{ACKNOWLEDGMENT}

This work was supported by the Waste Isolation Safety Assessment Program (WISAP) being conducted by Pacific Northwest Laboratory. This program is sponsored by the Office of Nuclear Waste Isolation, which is managed by Batte 1le Memorial Institute under contract EY-76-C-06-1830 with the Department of Energy.

Senior data analyst Dennis Friedrichs advice and assistance throughout the course of this work was appreciated. 
. 


\section{INTRODUCTION}

The main purpose of a computerized Sorption Information Retrieval System (SIRS) is to aid in the analysis of 1 arge amounts of experimental data. The following sections address the needs for sorption information retrieval system, details of the current WISAP data base, and suggestions for expanding the basic system if justified by future needs and uses.

Computer analysis is necessary because a single sorption-desorption experiment could have as many as 100 parameters describing it. Data on about 5,000 experiments exist at present, and several thousand more experiments are expected to be generated each year during the next few years. Information system users would like access to this information for purposes of anlaysis and comparison. Some statistical analysis of experimental data is desirable. To fulfill these data base goals - analysis and comparison - a system design approach has been identified. The proper system design depends on the specific needs of the users and the nature of information to be stored and retrieved.

An information retrieval system for the large amount of sorptiondesorption data is particularly important to help predict the migration of radionuclides that would be caused by the breach of a nuclear waste repository. If a waste repository is breached by intruding groundwater, radioactive wastes will be leached and radionuclides brought into solution. The most important barriers to radionuclide movement are retardation from engineered barriers and from the interaction between radionuclides and natural geologic media. The most common quantification of the retardation by geologic media is through the use of the adsorption distribution coefficient or Kd.

In most instances $\mathrm{Kd}$ is sensitive to the surface area, mineral composition, amorphous oxide, and organic content of the solid material, and the $\mathrm{pH}$, Eh, and chemical composition of the carrier solution. The Kd is also dependent on the species of nuclide present, its concentration and the hydrodynamics of the system. The interactions which occur as soluble radionuclides 
percolate through geomedia are presented in Figure 1. Therefore to properly identify, interpret, or use a Kd value for any nuclide a large amount of supplementary information is necessary. Consequently, a computerized storage and retrieval system will greatly facilitate the usefulness of the collected sorption-desorption information, both for basic research on nuclear waste-rock interactions and for applications in nuclear waste repository safety assessments. 


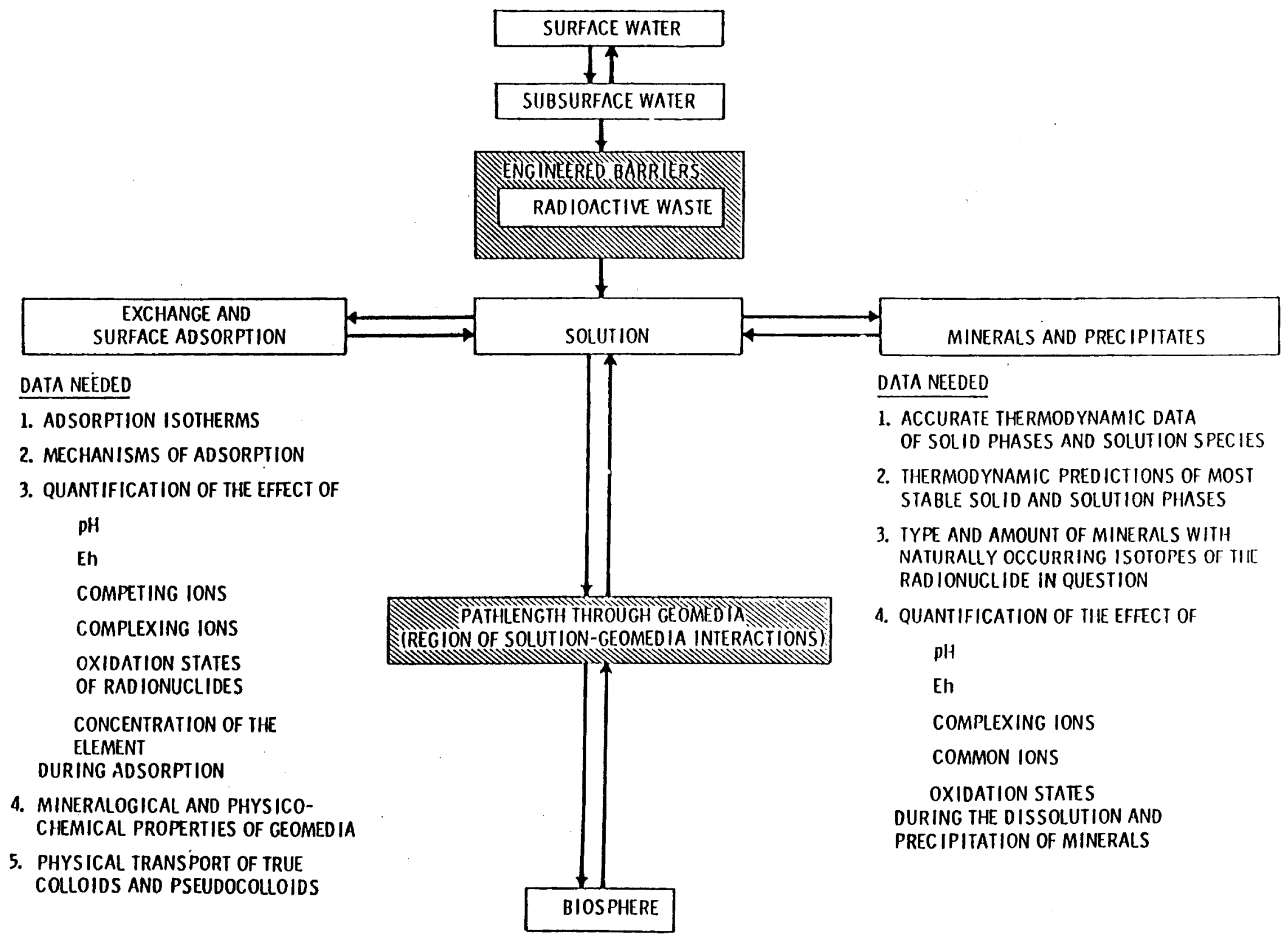

FIGURE 1. Radionuclide Interaction in Geologic Media 


\section{INFORMATION NEEDS}

Extensive supporting information (characteristics of the geologic mediagroundwater system) is necessary to establish the information system. Without this ancillary information, predictive, extrapolative and interpolative activities cannot be performed objectively. In the ideal case all the parameters listed below would be determined; in real instances as many of the parameters as economically or logistically possible should be measured.

Numerous characterizations should be performed on geologic media and the ir pore waters to allow calculations of migration rates or Kd's. The characterizations can be broken into two broad categories: physical or hydrologic, and geochemical. A list of characterizations and their relative importance follows. The relative importance is based on the assumption that insufficient time and funds will be available to perform the complete characterization. If on ly partial geochemical characterization is possible, concentration should be on the first seven items. For the physical and hydrologic characteristics items 4,5 and 6 or 7 are most important. Important Geochemical Characterizations:

1. Qualitative and quantitative mineralogy including primary and secondary crystalline materials, amorphous coatings, etc. determined primarily by $x$-ray diffraction, chemical treatment techniques, and petrographic examination. Calcium carbonate content and hydrous oxide content (amorphous and crystalline) as we 11 as aluminosilicate contents are most important. Scanning electron microscopy and microprobes can be used to determined microstructural mineralogy. These technqiues can be very important in assessing the differences between mineralogy and weathering environments of cracks and fractures from the bulk rock material.

2. Cation-exchange capacity

3. Pore water $\mathrm{pH}$, Eh

4. Pore water major cation content ( $\mathrm{Na}, \mathrm{Ca}, \mathrm{Mg}, \mathrm{K}$ ) 
5. Pore water major anion content $\left(\mathrm{Cl}, \mathrm{HCO}_{3}-\mathrm{CO}_{3}, \mathrm{SO}_{4}^{-}, \mathrm{NO}_{3}\right)$

6. Pore water $\mathrm{SiO}_{2}$

7. Organic content of geologic material.

Less Important Geochemical Characterizations:

1. Anion exchange capacity

2. Distribution of major cations on exchange sites

3. Pore water organic content especially potential ligands (humic, fulvic acids)

4. Pore water minor constituents especially naturally occurring isotopes of important waste nuclides (Sr, Cs, I, U, Ra) and chemically similar elements ( $\mathrm{Ba}, \mathrm{Rb}, \mathrm{Br})$.

For geologic environments that are presently devoid of water a saturated water extract should be prepared and the above mentioned pore water analyses performed.

Important Physical or Hydrologic Characterizations:

1. Hydraulic conductivity

2. Percentage saturation

3. Permeability

4. Water velocities

5. Surface area and particle size distribution (unconsolidated materials)

6. Porosity

7. Percentage fractures or fissures (consolidated material)

8. In situ temperature.

Unfortunately, the bulk of the $\mathrm{Kd}$ values reported in the literature is not accompanied by this supplementary information. The use of these partially undefined $\mathrm{Kd}$ values as predictors of the interactions with a media-solution system of interest may lead to improper conclusions. On the other hand, for the first-cut approximations for hypothetical scenarios and safety assessments, existing Kd values that are fully or partially defined can be used to establish limits or ranges of uncertainty. If the assessment is found to be very sensitive to $\mathrm{Kd}$, steps should be taken to obtain values which truly represent the interactions of wastes with the geologic media of interest. 
THE WISAP SORPTION DATA BANK

To facilitate the tabulation and synthesis of the large number of data needed to quantify nuclide retardation, a computerized information retrieval system has been established at Pacific Northwest Laboratory (PNL). The present concept and standard format of the WISAP Sorption Information Retrieval System are presented in Appendix $A$. The standard formats delineate all the currently needed information on rock, groundwater, nuclide characteristics and experimental methodo logy.

The computer can search on any of the six main categories described in Appendix $A$ and sort the data automatically. For example, if a listing of a 11 Kd data for basalt is wanted, the computer will tabulate all basalt data. If a user wants to compare Kd's from a salt brine across all rock types, a 11 brine information will be tabulated, etc. The computer system sorting capability could also be linked to statistical programs such that selected data will automatically be transferred from the data bank to the statistical program. After manipulation, the results can be displayed on a cathode ray tube or hard copies can be produced. In this fashion, means, standard deviations, covariances, or other pertinent statistical parameters for Kd can be obtained as a function of minerals surface area, cation-exchange capacity, groundwater composition, etc.

\section{POTENTIAL USES}

The Sorption Information Retrieval System is being set up interactively, such that the user is lead through the retrieval procedure step by step. It is being designed for geochemists, geophysicists, geologists and hydrologists, as well as nontechnical users. The output from the information retrieval system will not require a lot of technical interpretation. If a modeler needs Kd values for a particular scenario, the information retrieval system will inquire as to the type of scenario, and after the operator inputs on the keyboard, the computer will select possible choices and display them along with any other basic details requested. Those in Appendix A represent currently available information. 
With proper experimental design and media-water characterization, statistical methods can be used to relate the dependent variable (migration rate or Kd) to independent variables (rock type, solution type, etc.). Although the derived relationships do not prove cause and effect, they do allow prediction of trends. Thus from kd data on a finite number of rock, mineral and water types, estimates can be made of $k d$ values for other rocks and water environments not directly studied, if certain precautions are observed.

One example may be the use of predictor equations from adaptive learning network synthesis. In this synthesis of experimental data, a multinomial function is generated describing the $K d$ of a specified nuclide in terms of pertinent variables (e.g. rock, groundwater, etc.). This function can then be used for extrapolation, interpolation, or sensitivity analysis of the pertinent nuclide. Other examples of statistical manipulations might be the use of regression or covariances.

Other products that the data base can help provide are 1) the formulation of geochemical criteria useful for ranking the ability of media to isolate nuclear wastes, and 2) delineation of the more important variables which should be studied in greater detail in mechanism studies. 


\section{SYSTEM DESCRIPTION}

PURPOSE

The main purpose of the Sorption Information Retrieval System (SIRS) is to aid in the availability and analysis of large amounts of experimental data. Rapid selection and retrieval of available sorption data will help primarily two efforts: 1) experimental and theoretical research and 2) geohydrologic modeling. The main information system design considerations are:

- availability

- rapid access

- simple analysis

- graphic output.

SIRS is currently in the final stages of development with respect to software coding and data input. Additional coding, data input, and testing will be required to assess overall system performance.

\section{COMPUTER SYSTEM}

An interactive computer in the Water and Land Resources Department of PNL satisfies the design considerations listed above. The PDP 11/55 is a singleuser computer with a variety of graphic display capabilities. It is easily accessible to both experimental personnel and geohydrologic modelers. Data base control is accomplished with a light pen sensitive cathode ray tube (CRT) and keyborad. 300 megabytes of high speed disk storage provide rapid access of experimental data. Simple analysis of data is augmented by the availability of the International Mathematical and Statistical Library (IMSL). Any results can be presented on the CRT. In addition, histograms, graphs, covariance matrices, experimental data, etc. could be directed to either a Calcomp plotter or lineprinter for hard copy output when appropriate. The general hardware configuration is shown in Figure 2. Using this hardware and the experimental data format described in Appendix $A$, a detailed initial design of the data base software was conceived. 


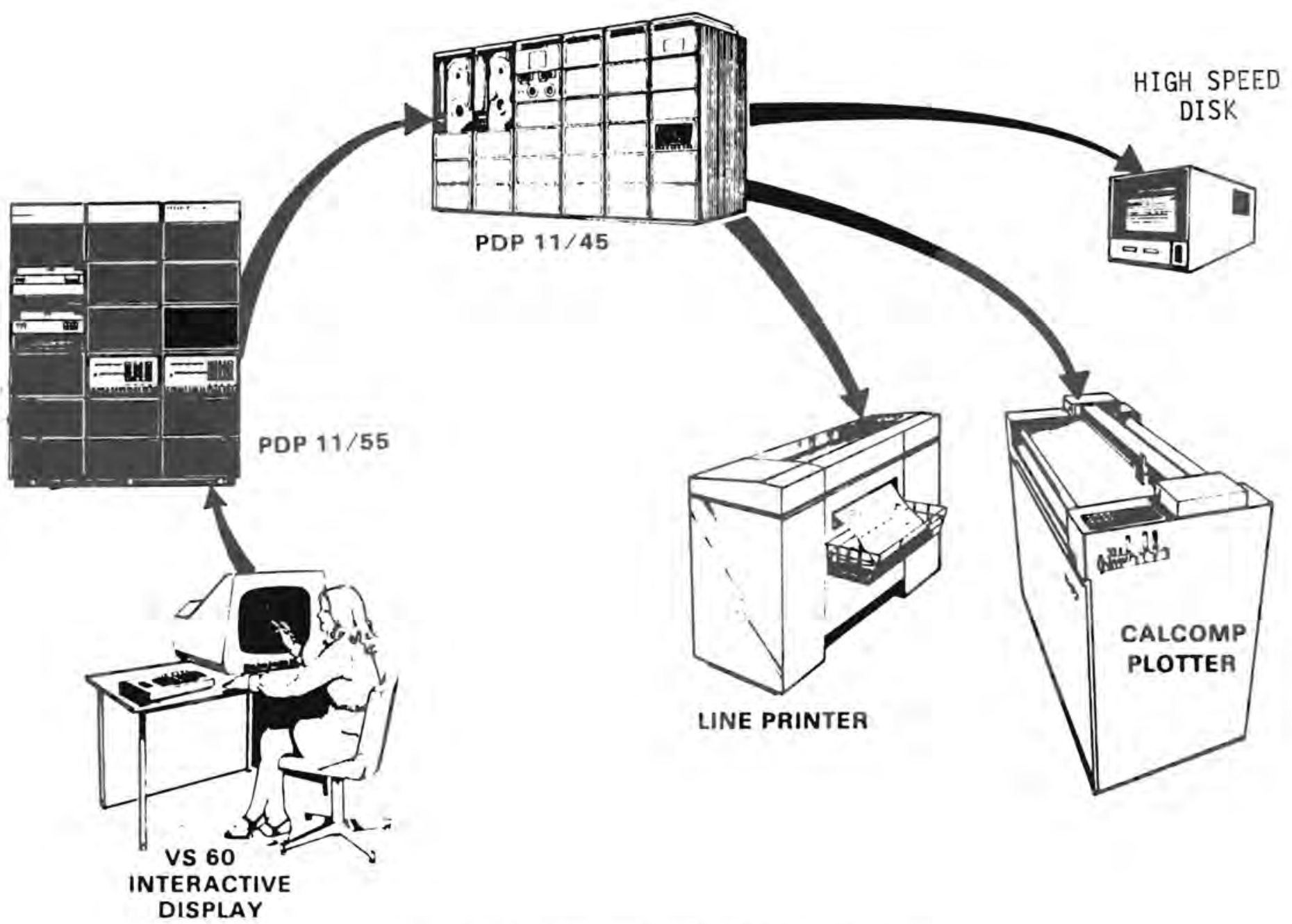

FIGURE 2. Computer Configuration 
DATA BASE FEATURES

The dominant function of the SIRS computer codes is to provide subsetting capability. The user will be able to access the entire set of experimental data and retrieve only desired subsets. The subset characteristics will be specified by the user through prompting commands on the light pen sensitive CRT. Once the experimental data for a particular subset are retrieved, the data could be statistically analyzed or manipulated. The results of any pertinent analysis will be hard-copied to an output device.

The internal organization of the data base, which is hierarchical (multiple levels) in nature, derives directly from the generic Kd coding form described in Appendix A, page A-1. The categories on the coding form supply all the information necessary to adequately describe a sorption experiment. Different category levels refer to subcategories within categories. For example in Figure 3, the category "METHOD" is a level 2 category under the level 1 category "EXPERIMENTAL DETAILS". Data categories extend down to the 4th level. Each possible category receives a four number index uniquely identifying it. The four number index identifying "METHOD" would be $2,1, \emptyset, \emptyset$. Indexing is the key to all data base manipulations. All presently conceived categories and their indices are shown in Appendix $B$.

To increase the data base retrieval speeds during analysis, a certain amount of preprocessing of data is necessary. Each piece of data from a single sorption experiment fits into a specific category. The preprocessing consists of constructing lists of experiments that contain data for any given category. When a user selects certain criteria for subsetting the data, he is actually specifying which categories to include in the analysis. The experiments which satisfy all criteria can then be selected from the data base. This method of sorting data is similar to a series of table lookup procedures. It sacrifices storage space to gain speed. All data files are stored on high speed disks in random access, binary files. 


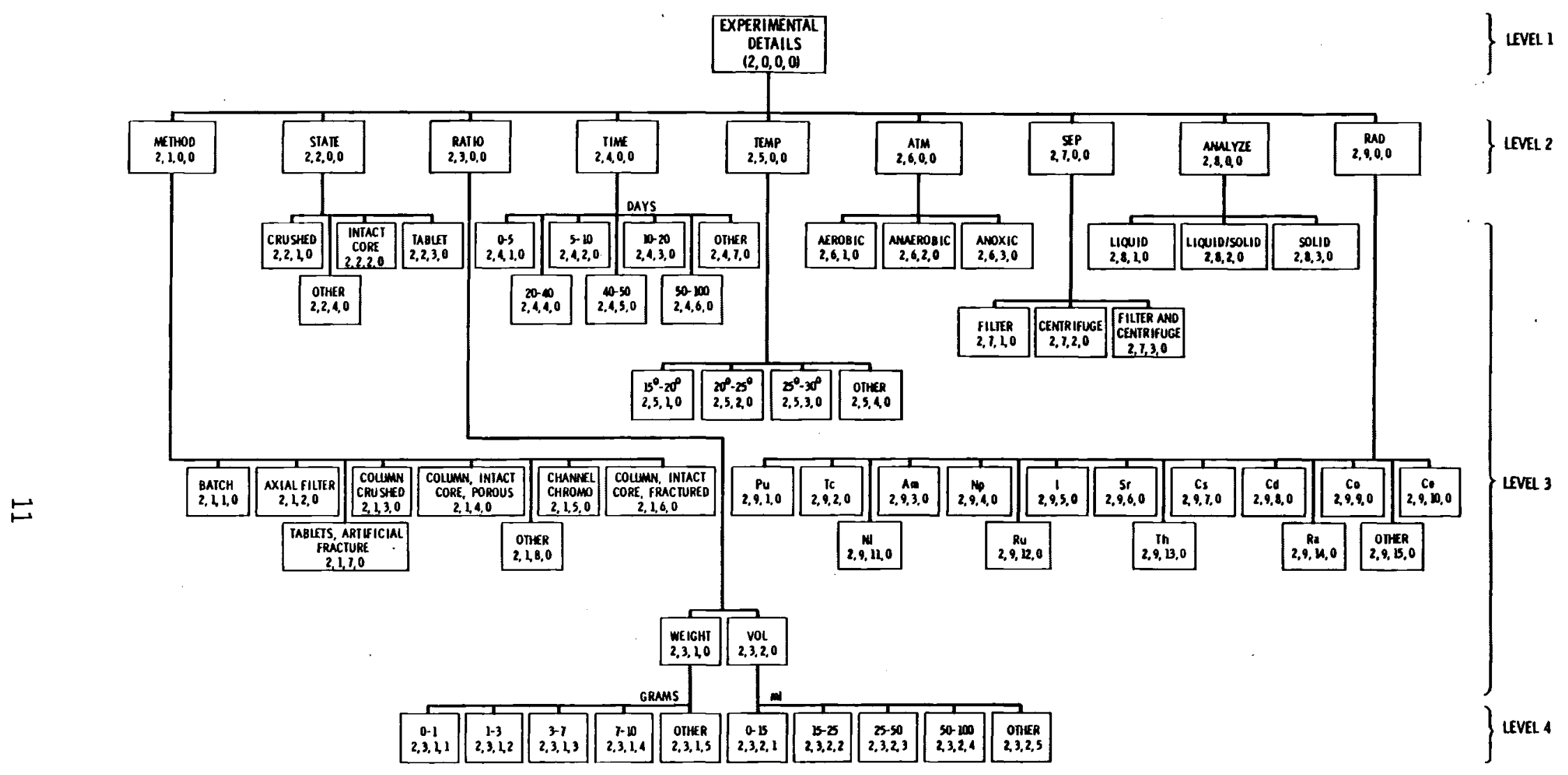

FIGURE 3. Experimental Details' Category Indices 
It is important to note that data base organization permits data to accommodate both numeric and alphabetic information. In the case of numeric data, the ranges of values of a particular variable are specified. This range then constitutes a category. For example, in Figure 3 under the level 2 category TIME is the box labeled $5-10(2,4,2,0)$ days. This is a range of values constituting a category. The exact value is not lost, but is contained in the experimental data file.

Ranges of values for a variable can be changed, as can any alphabetical category. The only requirement after changing a category is to regenerate the lists of experiments containing data from that category. This is the only way the data base can know of any changes.

The current version of SIRS is highly interactive. Rapid access, analysis, and graphic output characteristics were chosen over efficient, compact data storage. These choices were made possible by the unique computer hardware configuration in the Water and Land Resources Department. As long as the total disk space needed does not exceed 300 megabytes, the present version of the data bank should function satisfactorily for the purposes of WISAP-related efforts. In addition, computer codes should be able to function properly for any form of experimental data that can be structured into a series of 'category trees' similar to those in Appendix B. The precise method of data input is described in Appendix $C$. Data base quality assurance plans are outlined in Appendix D.

\section{EXAMPLES OF USAGE}

As an illustration of the current SIRS operation, several examples of usage can be shown. Figure 4 is a copy of the CRT display showing the four major functions of the data bank. They are:

- data bank generation (input and preprocessing),

- data bank checking (input data verification),

- data analysis (subsetting and analysis), and

- radionuclide inventory data display (calculation of radionuclide inventories as a function of time). 


\title{
SORPTION DATA BASE CONTROLLER
}

\author{
WORKING TASK CAPABILITIES:
}

DATA BASE GENERATOR

DATA BASE CHECKER

DATA ANALYSIS

INVENTORY DATA

FIGURE 4. Sorption Data Base Controller 
A data bank user might start in the generator program, input an experimental data file from disk, and preprocess the new information. The next step would be to spot check for the accuracy of the data. The user could then proceed to the data analysis program. Figure 5 represents the available level 1 categories. After choosing the "GEOLOGIC MEDIA" category, the available level 2 categories are displayed (Figure 6 ). This selection process continues to the lowest levels available (in this case the 3 rd and 4 th levels - Figures 7 and 8). The user can then choose any or all ranges showing, for example, percent of phyllosilicates present in the sample. The analys is routine can then search the data base for experiments satisfying a range of phyllosilicates or any combination of criteria. These experiments can then be displayed on the CRT. Also, any statistical analysis for this subset of experiments might be conducted and the results displayed. These steps typify the use of the current version of SIRS.

Presently the geochemical criteria are difficult to define fully or to quantify; thus an iterative process is envisioned. For the Sorption Information Retrieval System a list of provisional critieria will be prepared as data become available. The first few formulations will be based on the limited available data. As better data and a more thorough understanding become available, the criteria will be progressively updated. Such an iterative process may also identify areas in which additional study is necessary.

If the user were a geohydrologic modeler, the radionuclide inventory program would be used also. Figure 9 shows the cathod ray tube (CRT) output for this program. After choosing a starting inventory data file and an elapsed time, the computer routine calculates the remaining radionuclide inventory table up to a million years. This capability enables the modeler to see which radionuclides will be important for the given time frame. Knowing this, the data analysis routines previously described can be used to extract Kd values for the groundwater models. 


\section{DATA BASE, ANALYZER}

* 1. Reference

* 2. experimental details

* 3. Geologic media

* 4. aduedus phase (BEgIN)

* 5. aqueous phase (end)

* 6. NUCLIdDE

* 7. adsorption function

\section{STOP PROGRAM \\ DUTPUT}

TASK ROUTING: GENERATOR CHECKER ANALYSIS INVENTORY

ANALYZER OPTIONS:

IN I T I AL I ZE

SPECIFY LEVEL

* LEVEL 1

LEVEL 2

LEVEL 3

LEVEL 4

SEARCH DATA BASE

DISPLAY EXP.DATA

NEXT EXPERIMENT

PREVIOUS EXPERIMENT

STATISTICS 
DATA BASE ANALYZER

3. GEOLOGIC MEDIA

* 1. NAME

* 2. origin

* 3. total

* 4. mineralogy

* 5. $\mathrm{co3}$

* 6. $0 x$

* 7. CEC

* 8. AEC

* 9. SA
STOP PROGRAM

DUTPUT

TASK ROUTING:

GENERATOR

CHECKER

ANALYSIS

INVENTORY

ANALYZER OPTIONS :

IN I T I AL I ZE

SPECIFY LEVEL

LEVEL 1

* LEVEL 2

LEVEL 3

LEVEL 4

SEARCH DATA BASE

DISPLAY EXP.DATA

NEXT EXPERIMENT

PREVIOUS EXPERIMENT

STATISTICS

FIGURE 6. Data Base Analyzer - Level 2 


\section{DATA BASE ANALYZER}

3. GEOLOGIC MEDIA

4. MINERALOGY

* 1. tectosilicates

* 2. cyclosilicates

* 3. nesosilicates

* 4. inosilicates

* 5. Phyllosilicates

* 6. OXIDES

* 7. sulfates

* 8. sulfides

* 9. Phosphates

* 10. carbonates

* 11. Chlorides

* 12. OTHER

\section{STOP PROGRAM \\ DUTPUT}

TASK ROUTING:

GENERATOR

CHECKER

ANALYSIS

INVENTORY

ANAL YZER OPTIONS :

INITIAL I ZE

SPECIFY LEVEL

LEVEL 1

LEVEL 2

* LEVEL 3

LEVEL 4

SEARCH DATA BASE

DISPLAY EXP.DATA

NEXT EXPERIMENT

PREVIOUS EXPERIMENT

STATISTICS

FIGURE 7. Data Base Analyzer - Level 3 


\section{DATA BASE ANALYZER}

STOP PROGRAM

EUTPUT

TASK ROUTING:

GENERATOR

CHECKER

ANALYSIS

INVENTORY

ANAL YZER OPTIONS:

I N I I I AL I ZE

SPECIFY LEVEL

LEVEL 1

LEVEL 2

LEVEL 3

* LEVEL 4

SEARCH DATA BASE

DISPLAY EXP.DATA

NEXT EXPERIMENT

PREVIOUS EXPERIMENT

STATISTICS

FIGURE 8. Data Base Analyzer - Level 4 


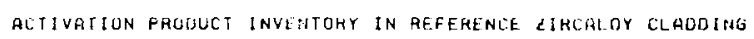

HUIIS HS FUHCTION OF HeCAY VIME GLL FUEL. CrCLE MOUES

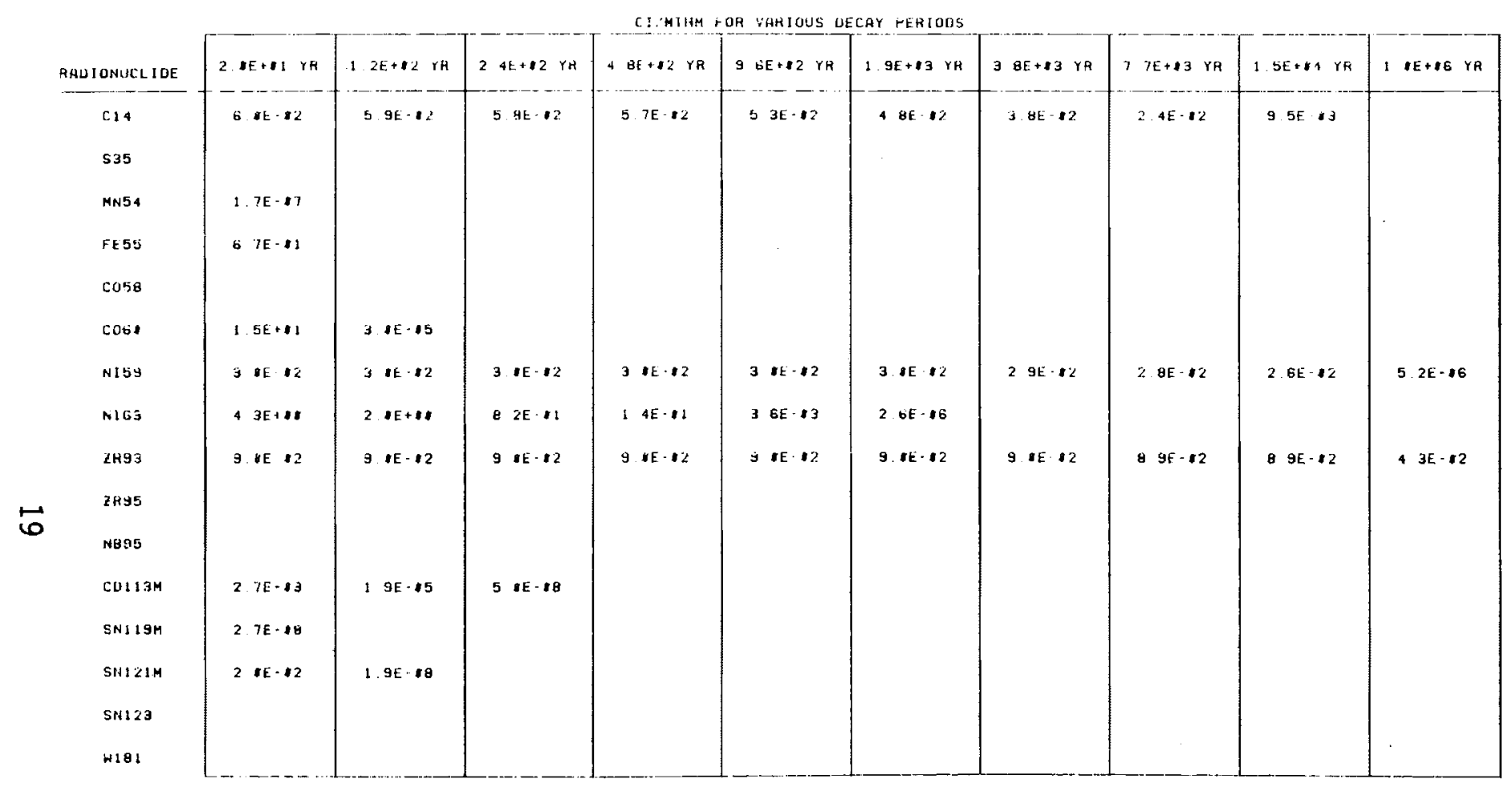

Periods aAe MeGSiheu from Reactor uischarge
INVENTORY I

INVENTORY 2

INVENTURY 3

INVENTORY 4

RETURN TO CONTROL

DATA SELECTION

PLOT FILE

PRINT FILE

PAGE FURWARD

PAGE BACKWARE 
In conclusion, the SIRS is an example of one approach for analyzing experimental data sets. It is highly interactive and its capabilities are best utilized by an on-site user. It is not capable of long distance prompting and interrogation. The current version is strictly a "hands on" facility with hard-copy capability. 


\section{CURRENT STATUS}

This report presents the status of the Sorption Information Retrieval System (SIRS) at the end of FY-1979. Improvements of the system, system testing, input of additional experimental data and initial system use are planned for FY-1980. A final report will be issued when the system becomes operational for efficient data retrieval.

During FY-1979, SIRS development occurred in four areas: data input, data retrieval and display, statistics, and data output. The data input computer codes are not extensive, but provide an essential function. They check keypunched experimental information for obvious errors and reformat the data slightly. In addition, selected tabulations of raw data before and after computer processing will be important steps for assuring data integrity. These data input computer codes are partially complete. The selective data retrieval and display software is the heart of the data base and constitutes a major effort. This work is essentially done. The groundwork for simple statistical analys is of selected data has been laid; however, little effort has been devoted to this potentially valuable capability. The hard copy data output programs are partially complete. The magnitude of effort here will depend on the types of output desired by data base users. In summary, a limited amount of sof tware development is necessary to allow functional manipulation of the data. Undoubtedly, future data base use will identify new software development needs.

Data input and quality assurance work constitute a major portion of the effort in any computerized data base. The WISAP FY-1977/78 data consist of about 5,000 sorption experiments; 2,100 of the se have been coded and keypunched and are in the final stages of editing and implementation. Once implemented, data will be checked for errors and the whole data input process will be reviewed. New data input methods for minimizing errors have already been identified. Identified changes will be implemented for all future data input. 
Once the data integrity is reasonably assured, the data base system performance can be assessed. Geoscientists can then use the rapid data retrieval and interactive presentation of results to analyze and compare various experimental parameters. The greatly increased speed of data perusal by geoscientists should encourage $f$ ar greater use of the data. Ideally, simple statistics would be implemented to facilitate objective quantification of the data. For example, means, variances, and covariances would be very helpful. Rapid retrieval, comparison and analysis would be documented by outputting results to hard copy devices such as a line printer or plotter. Interchange between geoscientists and systems analysts resulting from system use will identify improvements for overall performance. Ultimately, geoscientists can begin to assess the potential analytical utility of SIRS. 
APPENDIX A

CODING FORMAT 
$\frac{\text { Generic Kd Coding Form }}{(\text { Revision 1) }}$

\begin{tabular}{|c|c|c|c|c|c|}
\hline \multirow{10}{*}{$\begin{array}{l}\text { A. Name } \\
\text { B. Lab } \\
\text { C. Source } \\
\text { D. Quality } \\
\text { E. Date Submitted }\end{array}$} & Exp. Details & Geologic Media & Aqueous Phase & Nuclide & Adsorption-Function \\
\hline & A. Method & A. Name & A. When & A. Iso & A. $\mathrm{Kd}$ \\
\hline & B. State & B. Origin & B. Macro & B. Conc & B. Units \\
\hline & C. Ratio & C. Total & c. Trace & C. Spe & C. Dir \\
\hline & D. Time & D. Mineral & & D. Add & D. Num \\
\hline & E. Temp & E. $\mathrm{CO}_{3}$ & & E. Loading & \\
\hline & F. ATM & & & & \\
\hline & G. SEP & & & & \\
\hline & H. Analyze & & & & \\
\hline & I. Rad & & & & \\
\hline
\end{tabular}




\section{EXPLANATION OF Kd CODING FORM (REVISION 1)}

\section{Cätegory I. Reference}

A. Name of Investigator who is reporting results, person who performed experiments, or the person most capable of answering questions on the data. We would like to be able to track each data point back to a knowledgeable person.

B. Lab affiliation of investigator named in $A$.

C. Source where one could find the results published and described. Please use the following format:

Author's names, (date), title of paper, journal or lab report and number, publisher where applicable, page number.

If unpublished, use UNP.

D. Quality refers to one's confidence in the data. A critical assessment should be performed which includes identification of limitations, such as lack of certain parameter characterization, unexplained perterbations, etc. For conciseness, we have chosen a five category value system:

1. Excellent quality

2. Above average quality

3. Average quality

4. Below average quality

5. Poor quality

Because this categorization is arbitrary, comments as to why you gave the data are given certain rating are welcome. We would consider the excellent Category to include Kd data on which complete characterization of media, solution, and nuclide are available and that have been reproduced several times with good precision.

Average quality would leave some characterization work ill-defined (those which are least important and most costly to determine, have not been repro-

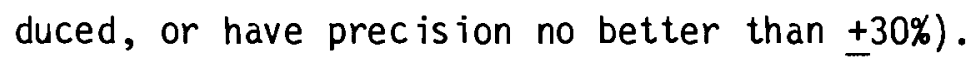


Below àveráge data show meager system characterization, little reproductibility, or identified experimental limitations.

E. For qua lity assurance purposes each data point needs to be dated as to when it was submitted to the computer (calendar year).

\section{Category II. Experimental Detāils}

A. Wethod refers to batch, axial filter, column, intact core, channel chromatography, etc. For batch add more detail as to whether cold washes and blank corrections were used. For example, use mnemonics such as

$\operatorname{BATCH}(3 W, B C)=$ batch, three cold washes, with blank tube sorption correction

BATCH $(O W)=$ batch, zero cold washes and no correction.

B. State of geologic medià such as crushed $40 \mathrm{~m}$; intact core $2.5 \mathrm{~cm} \mathrm{diax}$ $5 \mathrm{~cm}$; táblet $1 \mathrm{~cm} \times 0.5 \mathrm{~cm}$; crushed $30-80 \mathrm{~m}$, etc.

C. Ratio of solids to solution for batch $\mathrm{Kd}$; for columns include pore velocity or column velocity (for exämple, $1 \mathrm{PV}=1 \mathrm{~cm} / \mathrm{hr} \quad \mathrm{CV}=0.5 \mathrm{~cm} / \mathrm{hr}$ ) and porosity and column bulk density = porosity $\mathrm{Bd}=$ bulk density

D. Time of contact such as shäking time for batch system or residence time in flow through columns $(h)=$ hours, $(d)=$ days

E. Temp is the temperature of the experiment in ${ }^{\circ} \mathrm{C}$.

F. $\mathrm{ATM}$ is the equilibrating atmosphere air, $\mathrm{N}_{2}, \mathrm{Ar}, 10 \% \mathrm{CO}_{2}-90 \% \mathrm{Ar}$, etc.

G. Sep separation technique; did you use filters and median pore size or centrifugation, include approximate g's?

$\operatorname{FIL}(.4)=$ filter $0.4 \mathrm{~m}$

$\operatorname{CEN}(50)=$ centrifuged at $50 \mathrm{~g}$ 's where $\mathrm{g}=980 \mathrm{cgs}$ units

H. Count state whether the $\mathrm{Kd}$ is determined by counting LIQUIDS on ly or SOLID and LIQUID

$$
\begin{aligned}
& L / L=\text { liquids on ly } \\
& S / L=\text { solid and liquid }
\end{aligned}
$$


I. RAD List other radio isotopes which were run simultaneously in the experiment just in case we determine certain nuclides affect other nuclides.

Example: $\mathrm{Sr}, \mathrm{Cs}, \mathrm{Tc}$ means these isotopes were run together.

\section{Cätegory III. Geologic Media}

A. Name Use the generic name of the rock or mineral; basalt, granite, montmorillonite, etc.

B. Origin Geographic description, formation information, etc.

Eleana sha le, Sentinel Gap basait, Argillaceous Shale Wards \#404561, etc. For controlled sample rocks that we provided, where in doubt we can add the description.

C. Total Chemical composition as oxides $\left(\mathrm{SiO}_{2}, \mathrm{Al}_{2} \mathrm{O}_{3} \mathrm{TiO}_{2}, \mathrm{FeO}, \mathrm{MnO}\right.$, $\mathrm{Ca} \mathrm{O}, \mathrm{MgO}, \mathrm{K}_{2} \mathrm{O}, \mathrm{Na}_{2} \mathrm{O}, \mathrm{P}_{2} \mathrm{O}_{5}$, etc) in \%.

D. Mineräls Present in rock sample, list major ones first, minor ones last; if possible in order of composition (largest first). If there are quantitative estimates add this information as $\%$ and $\operatorname{tr}=5 \%$.

E. $\underline{\mathrm{CO}}_{3}=$ carbonàte content of rock

F. $\underline{\underline{O X}}=$ hydrous $\mathrm{Fe}, \mathrm{Mn}, \mathrm{Al}$ oxides content of rock

G. $\quad \underline{C E C}=$ cation exchange content of material, units $=$ meq $/ 100 \mathrm{~g}$. Specify $\mathrm{pH}$ of system (typically $\mathrm{pH}=7$ ).

H. $\underline{A E C}=$ anion exchange content of material, units $=$ meq/100g. Specify $p H$ of system.

I. $S A$ = surface areá; use "EG" for ethy lene glycol, "BET" for gas adsorption, use units $\mathrm{m}^{2} / \mathrm{g}$, for example, $\mathrm{EG}(1.3)$

\section{Category IV. Aqueous Phase}

A. When measured; $B E G$ signifies before tracer adsorption begun, END signifies at the same time as Kd determined. 
B. Mäcro Constituents include:

(1) $\mathrm{pH}$

(2) Eh (units vs S.H.E.)

(3) $\mathrm{Na}+2$

(4) $\mathrm{Ca}$

(5) $\mathrm{K}_{+2}$

(6) $\mathrm{Mg}$

(7) $\mathrm{Cl}^{-}$

(8) $\mathrm{HCO}_{3-2}-\mathrm{CO}_{3}-2$

(9) $\mathrm{SO}_{4}$

(10) $\mathrm{SiO}_{4}$

C. Trace constituents include:

(11) $\mathrm{NO}_{3}, \mathrm{ppm}$

(12) Organic carbon

(13) B

(14) Trace metals or anything else measured

Cátegory V. Nuc lide

A. ISO Isotope used such as ${ }^{237} \mathrm{Pu},{ }^{95 \mathrm{~m}_{\mathrm{Tc}}}$, etc.

B. CONC Concentration added to groundwater in $M=$ molarity. Include any Cärrier if present.

C. SPE Species or valence state added if known; also if the valence state distribution was determined after equilibration state, such as:

Pu(VI) BEG; Pu(IC) $15 \%, P u(V) 50 \%, P u(V I) 10 \% E N D$

means the original spike was $100 \% \mathrm{Pu}(\mathrm{VI})$, and after shaking the final distribution wàs às shown. 
D. ADD describes how the tracer was added to the groundwater, such as DRY means evaporated to dryness and gw added; WET/PH/3DF0.4 means a small aliquot of liquid tracer was added to the groundwater, the system re-pH'ed to the appropriate value and shaken for 3 days to filtration through $0.4 \mathrm{~m}$ filters before usage.

DRY/1DC50 means the dried spike was brought back into solution equilibrated for one day, and centrifuged at $50 \mathrm{~g}$ 's before usage.

E. Loading describes (a) the percent of total exchange capacity of the adsorbent fill with the nuclide of interest or (b) the mass of nuclide adsorbed/mass of adsorbent at the condition when the $K d$ measurement is performed. This value can be calculated from knowledge of the cation or anion exchange capacity in case (a) and mass balance considerations. One must know the original mass of nuclide used in each experiment.

\section{Category VI. Adsorption Function}

A. Kd Place the value for $K d$ or $R d$, whatever you prefer to call it. If a retardation factor is determined in a flow-through column as a function of water velocity, designate by the symbol RF.

Where several measurements were made, also give the standard deviation, such às

$75 \pm 12=\mathrm{a} K d$

(RF) $60 \pm 30=$ retardation factor

B. UNITS $\mathrm{ml} / \mathrm{g}$ or $\mathrm{ml} / \mathrm{m}^{2}$ or LESS = unit less

C. DIRECTION ADS = adsorption direction

DES = desorption direction

A spike addition to a column would be ADS-DES

D. $\underline{\text { NUM }}=$ number of observations used to derive data point, for example $3=$ triplicate samples 
Example of a Ratch Kd Experiment by Relyea

PNL Batch Kd for Microcline

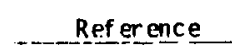
A. J. F. Relyea
B. PNL
C. WISAP Task 4
Contractor's
Informat ion
Meet ing Pro-
ceedings, $2-5$
1978 , to be
pub 1 ished
D. 2
c. 1978
B. Crushed
C. $0.5 \mathrm{~g} / 15 \mathrm{ml}$
D. $29 \mathrm{~d}$
E. $25 \mathrm{C}$
F. Air
G. Con (70)
H. $L / L$
I. $\mathrm{Sr}, \mathrm{Cs}$

Geologic Media

\section{A. Microcline}

B. Parry Sound Ontarin
(Hard's Scient if ir.)

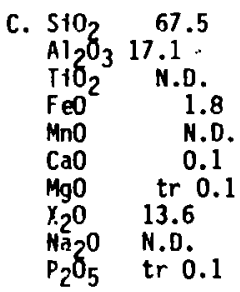

D. Microcline - $83 x$ $\left(\mathrm{K}_{3.95}\right)\left(\mathrm{Al}_{3.95}\right.$ Sl 12,05$) 0_{32}$ (Si0)

Calcite - 1 to $2 x$ $\mathrm{CaCO}_{3}$ Garnet - $1 \%$ Almand ine-Pyrope Garnet, ( $\mathrm{Fe}_{2.69}$ M94.14)( $\mathrm{Fe}_{1} . \mathrm{PO}^{\circ}$ $\mathrm{Al}^{\left.1.47, \mathrm{Si}_{5.53}\right)}$

$0_{24}$

E. $1 \%$

F. Not determined

G. $1.2+0.2, \mathrm{pH}=7$

H. Not determined

I. E.G. $(6.1+1.0)$

\section{Aqueous Phase}

A. Beg.

A. End

B. $\mathrm{pH}$ Eh(mv) U.2

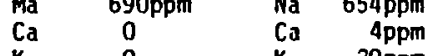

$\begin{array}{llll}K & 0 & K & 20 \mathrm{ppm}\end{array}$

\begin{tabular}{|c|c|c|}
\hline $\begin{array}{l}\mathrm{MO}_{3} \\
0 . \mathrm{C} . \\
\mathrm{B} \\
\text { Tr.Mat }\end{array}$ & $\begin{array}{l}\text { UNK } \\
\text { UNK } \\
\text { UNK } \\
\text { UNK }\end{array}$ & $\begin{array}{ll}\mathrm{NO}_{3} & \text { UWK } \\
\mathrm{OC}^{2} & \text { UNK } \\
\mathrm{B} & 2.8 \mathrm{ppm} \\
\text { Tot.Fe } & 9.1 \mathrm{ppm} \\
\text { Tot.P } & 0.2 \mathrm{ppm} \\
\text { Tot.Al } & 4.8 \mathrm{ppm}\end{array}$ \\
\hline
\end{tabular}

$\begin{array}{llll}\mathrm{Mg} & 0 & \mathrm{Mg} & 0 \\ \mathrm{Cl} & 0 & \mathrm{Cl} & 9.4 \mathrm{ppm}\end{array}$

$\mathrm{HCO}_{3} \quad 1350 \mathrm{ppm} \quad \mathrm{HCO}_{3} 1571 \mathrm{ppm}$

$\begin{array}{lllll}\mathrm{CO}_{3} & \mathrm{O} & & \mathrm{CO}_{3} & 75 \mathrm{ppm} \\ \mathrm{SO}_{4} & 0 & & \mathrm{SO}_{4} & \mathrm{NO} \\ \mathrm{Si}^{3} & & 0 & \mathrm{Si}^{\prime \prime} & \mathrm{PPm}\end{array}$

$\mathrm{Si}^{\mathrm{SO}^{4}} \stackrel{\mathrm{NO}}{\mathrm{NPm}}$

C.
Nuclide

\section{A. TC}

B. (approx.) $1 \times 10^{-8}$

C. $\mathrm{TCO}_{4}$ Beg

D. Wet/pH/7DFO.45

E. Not determined
Adsorption-Function

$$
\text { A. } 0.61 \pm .13
$$

B. $\mathrm{ml} / \mathrm{g}$

C. Adsoption

D. 3 reps 

APPENDIX B

CODING TREES OR DATA CATEGORIES 
The following organization charts or "coding trees" show the relationship of the data base format (Appendix A) and the indexing system used by the computer routines. This indexing system provides the basis for a 11 data processing.

Note: One difference exists with the Appendix B representation of the Appendix A format. AQEUOUS PHASE category is divided into two separate categories - AQUEOUS PHASE BEGIN and AQUEOUS PHASE END. 


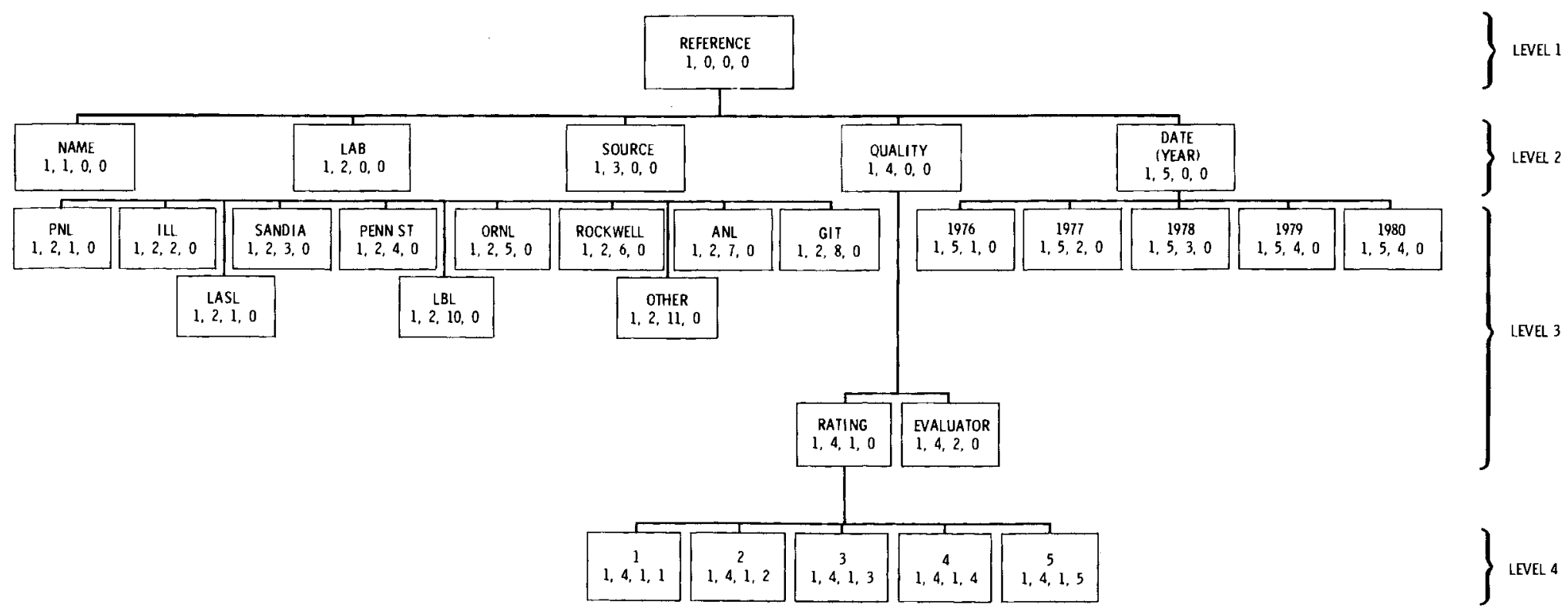

'Reference' Category Indexing Structure 


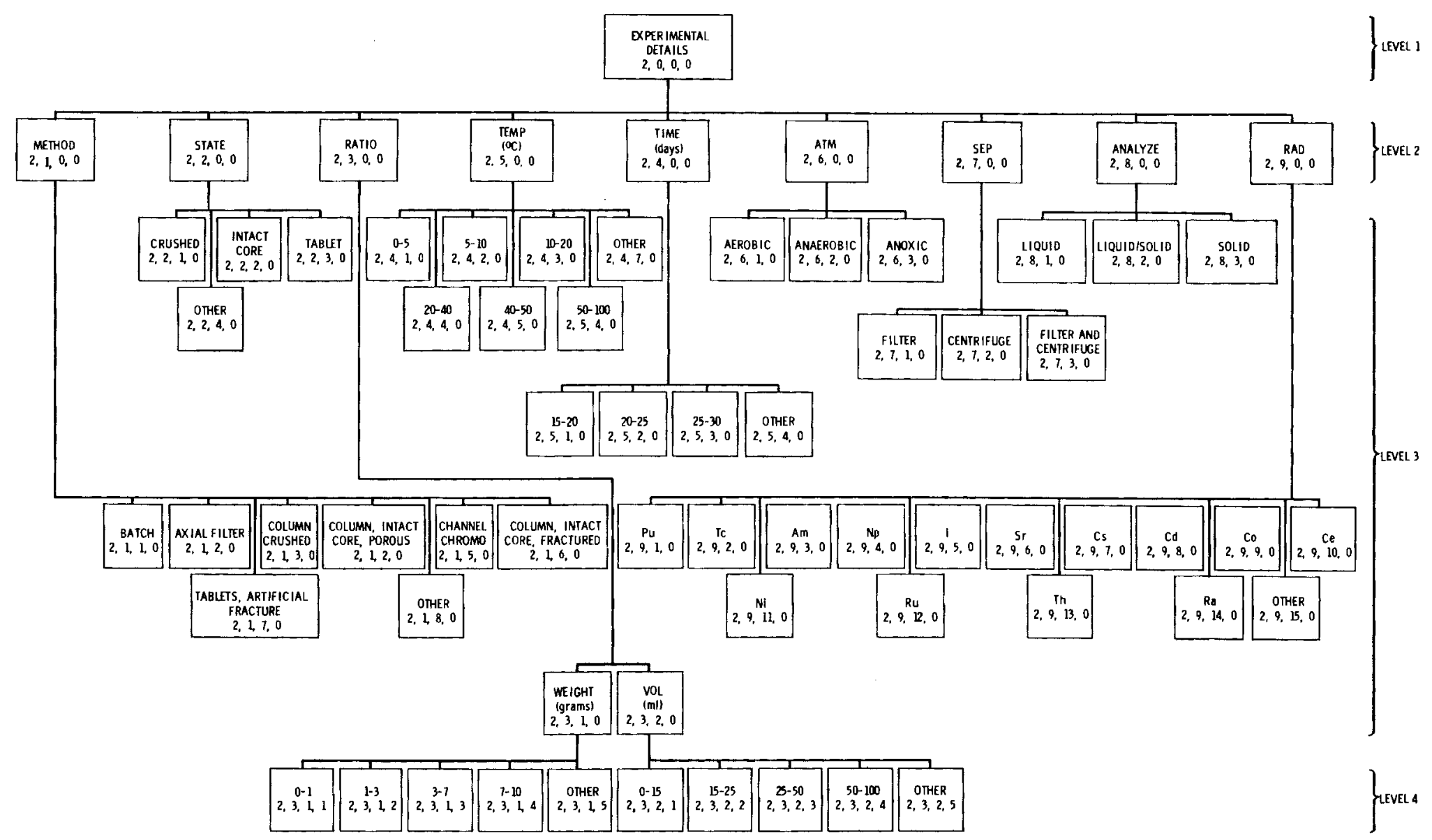

'Experimental Details' Category Indexing Structure 


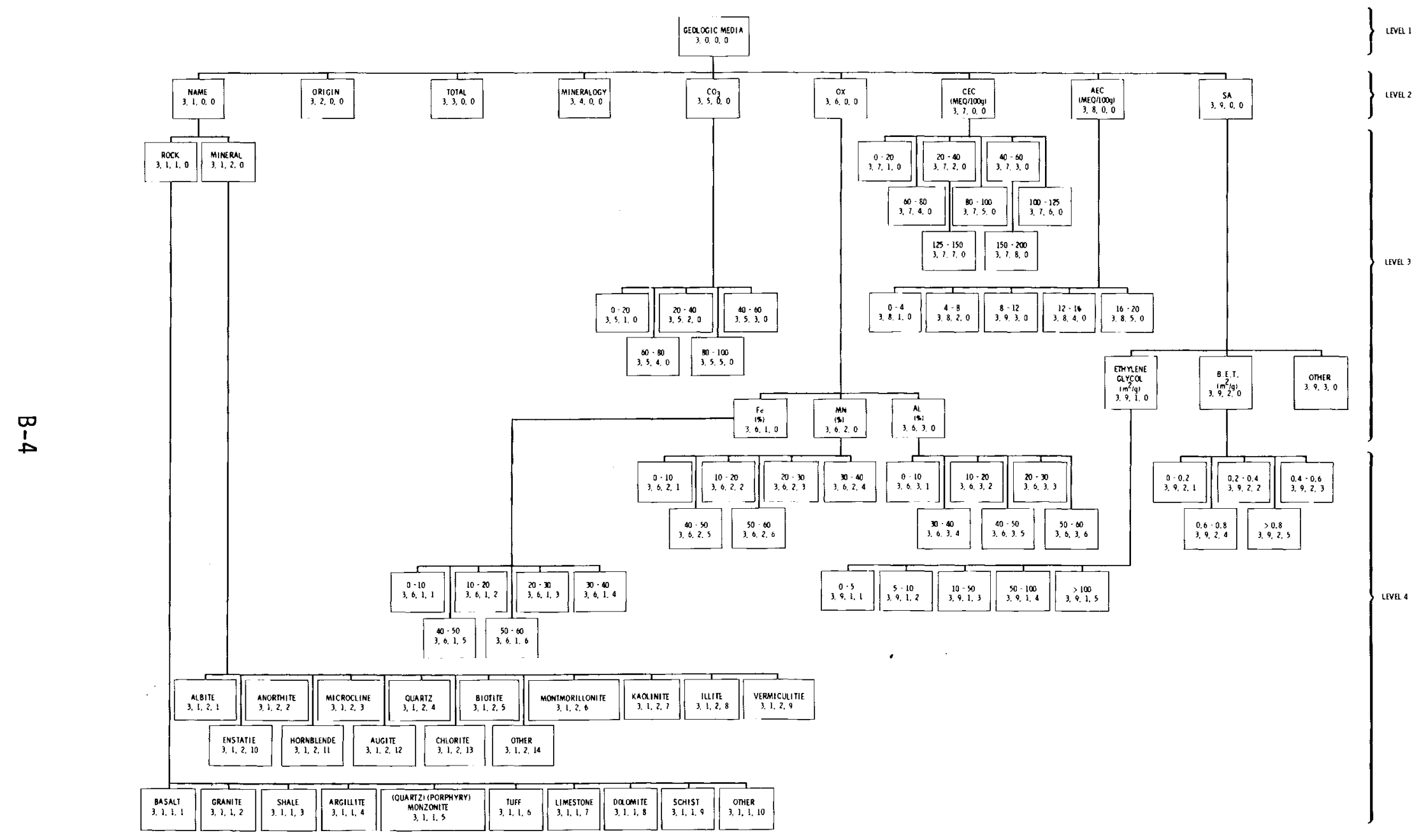

'Geologic Media' Category Indexing Structure 
'Mineralogy' Subcategory (under 'Geologic Media' category) Indexing Structure 


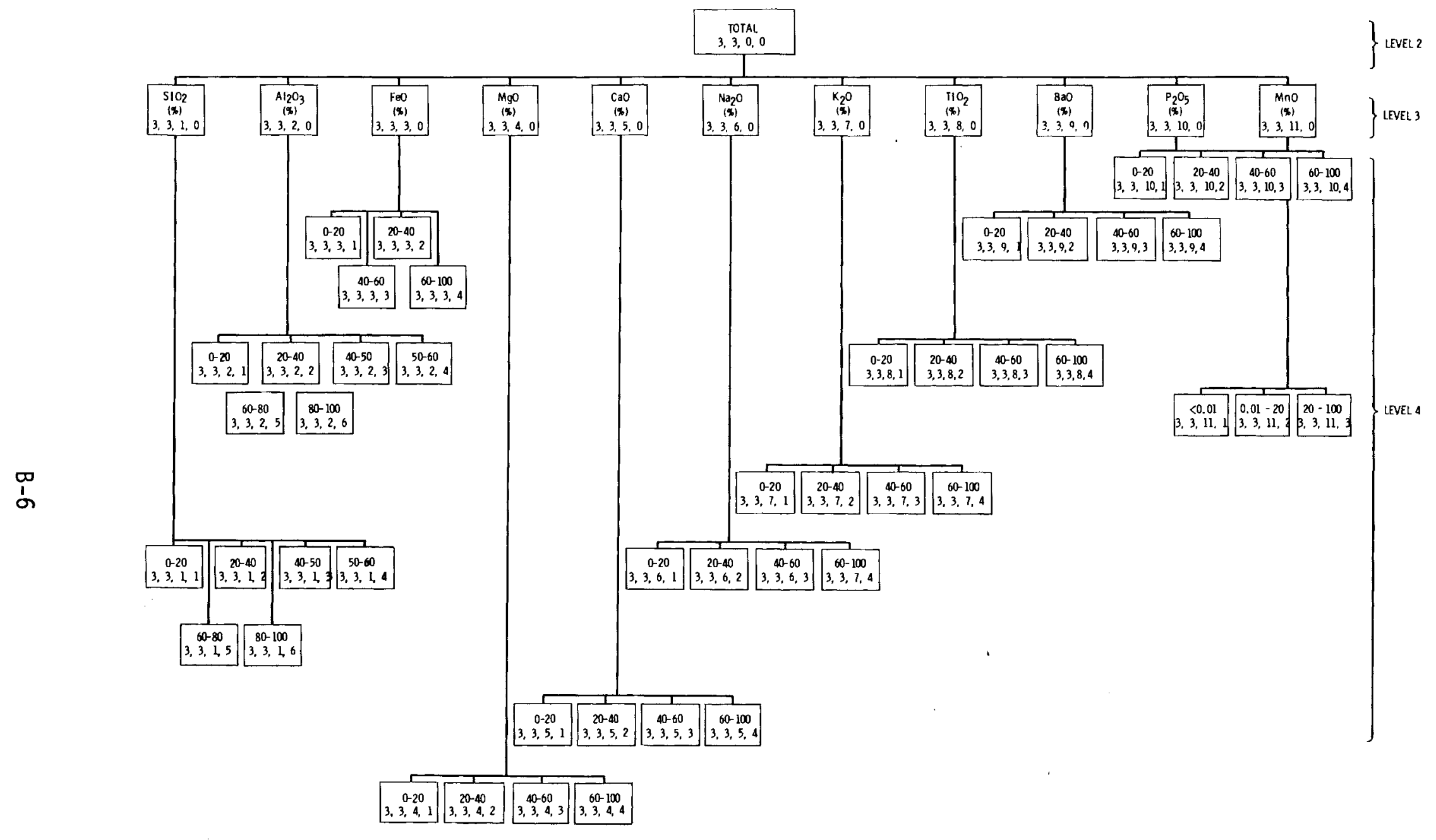

'Total' Subcategory (under 'Geologic Media' category) Indexing Structure 


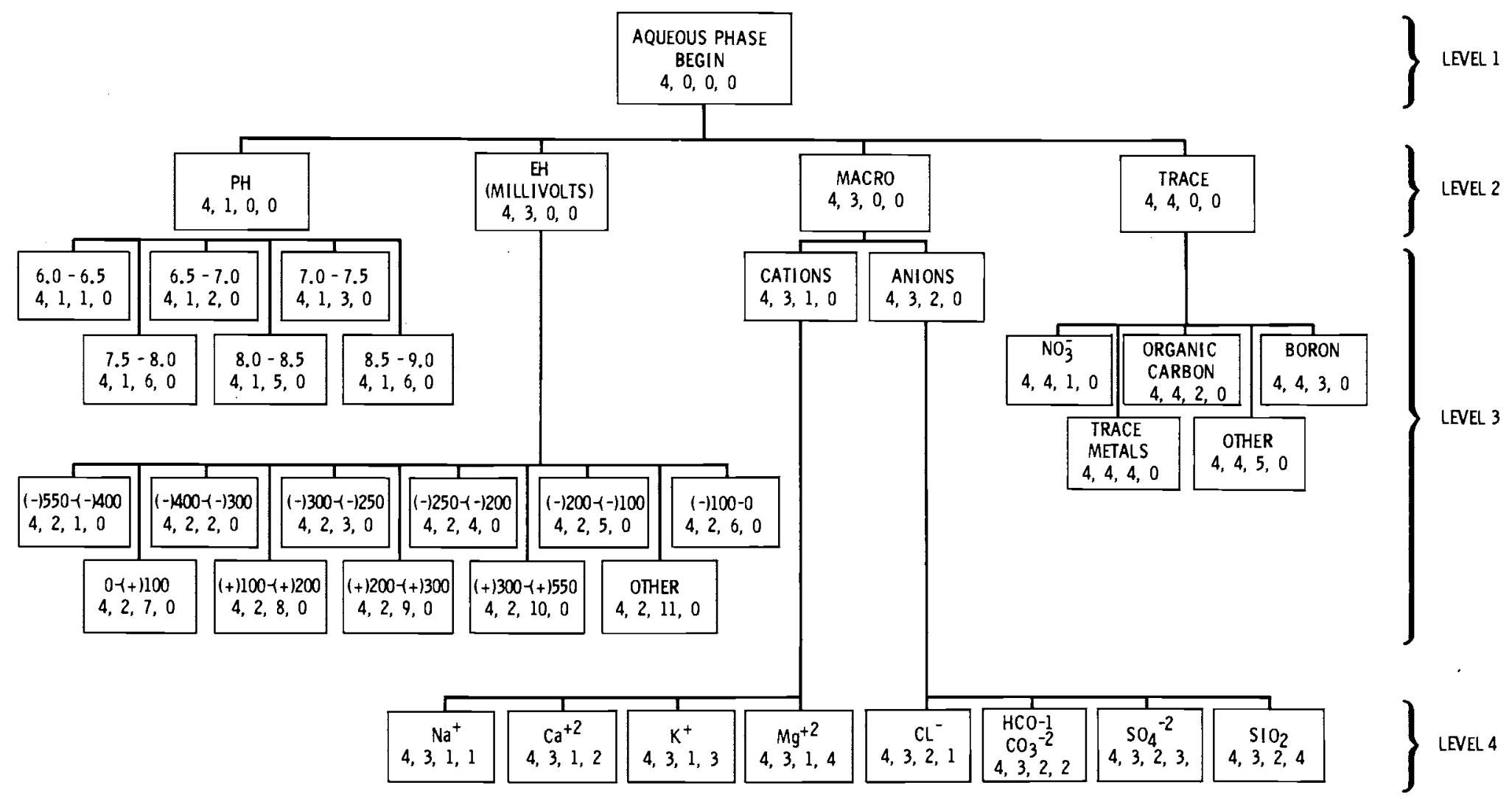

'Aqueous Phase (Begin)' Category Indexing Structure 


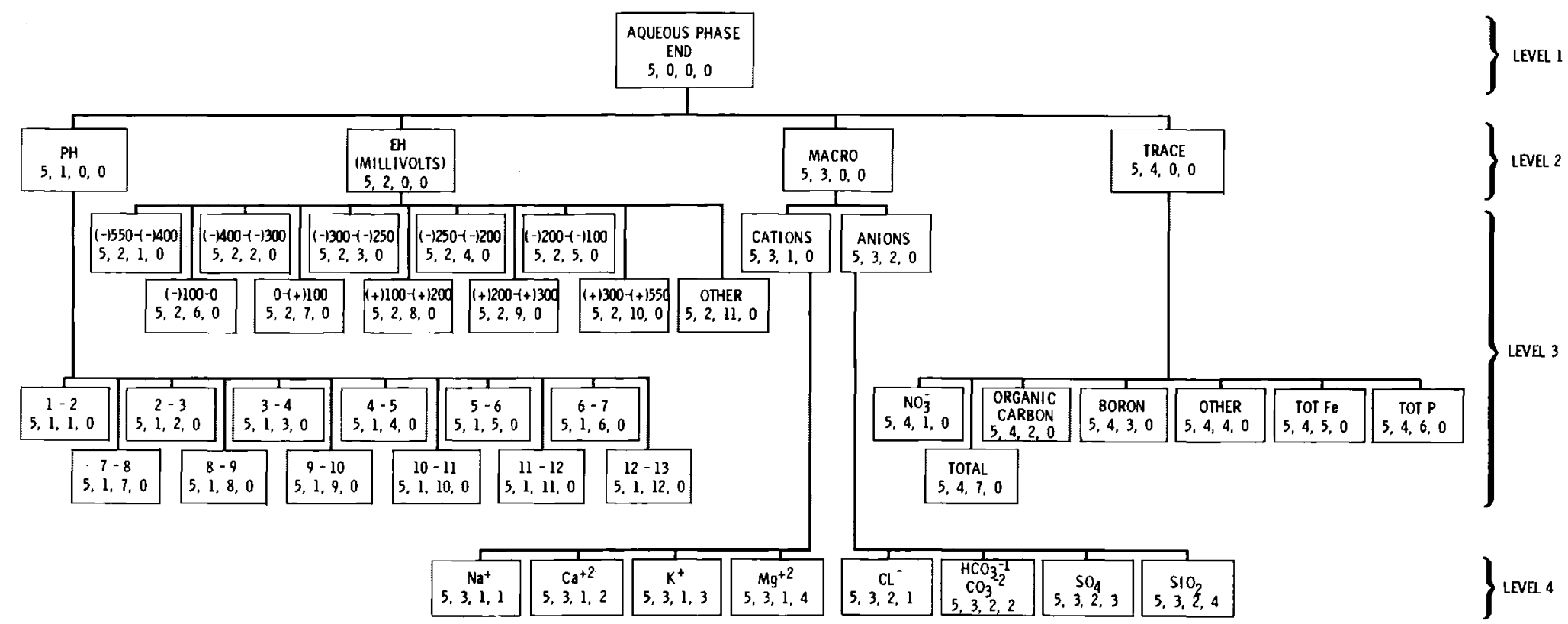

'Aqueous Phase (End)' Category Indexing Structure 


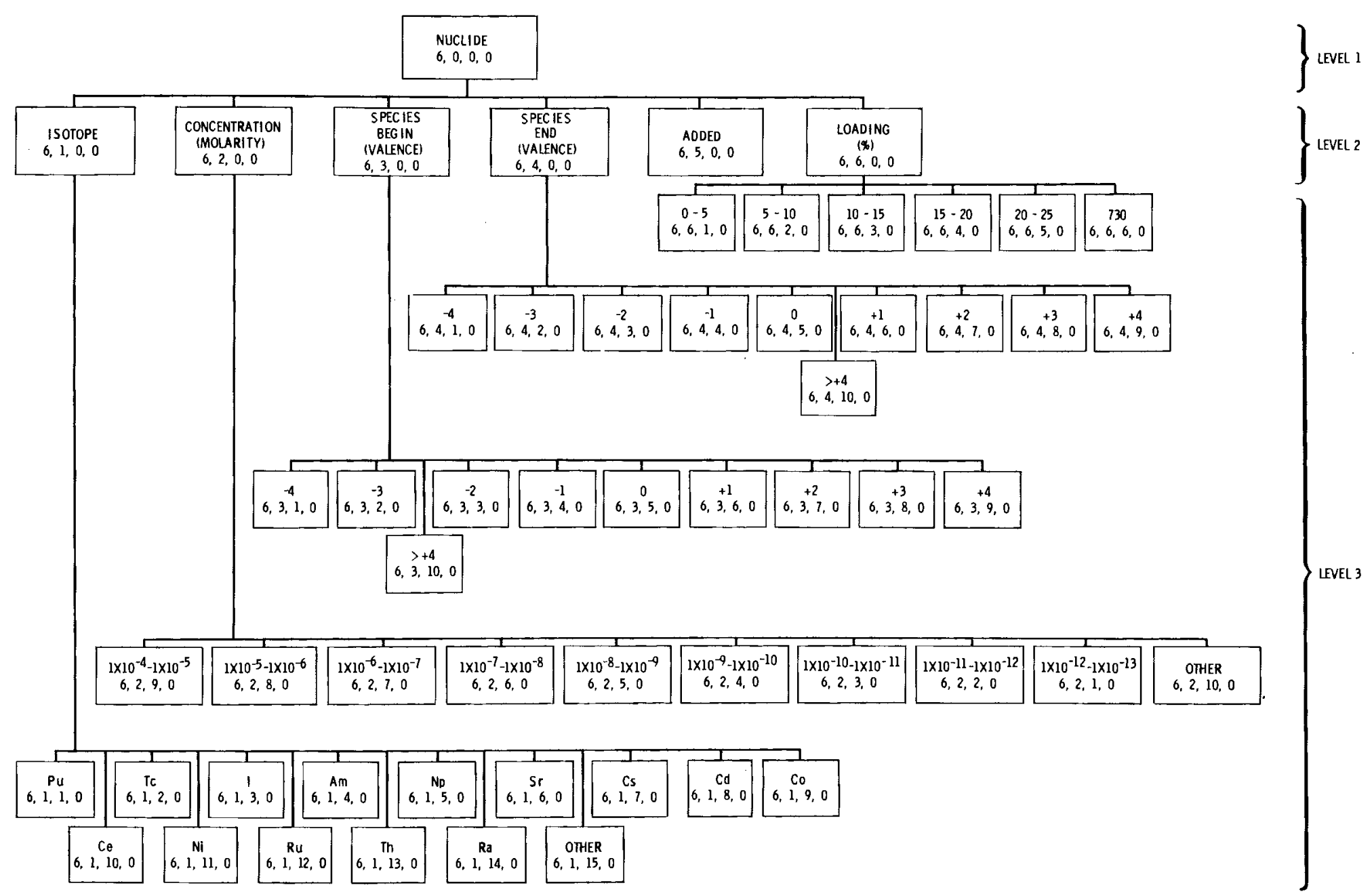

'Nuclide' Category Indexing Structure 


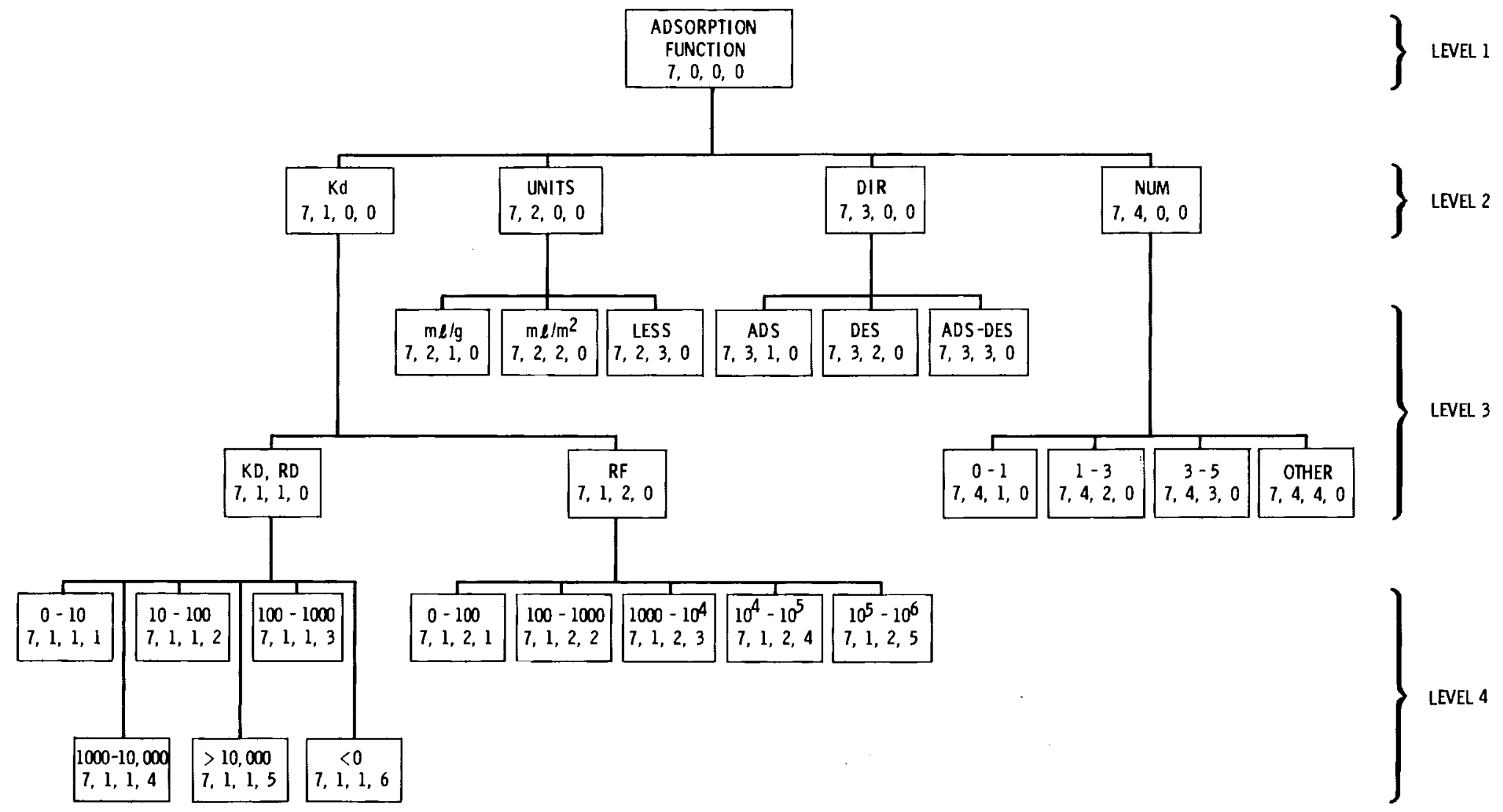

'Adsorption Function' Category Indexing Structure 
APPENDIX C

DATA INPUT METHOD 
In the past (pre-FY-1980), experimental data from WISAP contractors has been received in a generally consistent format (Appendix $A$ ). Th is data in turn has been rendered to a format consistent with the coding trees (Appendix B). In FY-1980 PNL contractors will submit data in the coding tree form. This avoids the conversion of data by PNL personnel from coding form to coding tree. The advantages of this action are:

- Elimination of extra work at PNL (significant)

- Elimination of re interpretation of data. (This may be hard to understand. However, each conträctor has his/her own shortcuts and interpretations of the coding form. This causes problems for PNL staff and may result in lost or inaccurate transmission of data.)

- Elimination of extra work by contractors (contractors wili operate to mininize the work on their end and avoid duplication).

- Minimize the amount of handling and number of people in contact with the dàtâ.

In essence, the coding form and coding tree are representations of the same thing. Both serve functions. The coding form is more descriptive than the coding tree and is necessary for the experimenter to be aware of what information is to be recorded. The coding tree is a more quantitative representation of the coding form that the computer requires for its function. However, PNL does not need a physical copy of experimental results in the coding form of Appendix $A$. All information required by the coding form can be recorded via the coding trees of Appendix $B$. There may be some exceptions, but notes from the contractor should suffice. The use of the coding trees by the contractor for recording experimental results should be simple. Each piece of data or information to be recorded should be traceable to a particulär box with in the coding tree. All data or information is recordable in three basic types - as a number, as à label or as a comment for any given category. First one must locate the unique index identifying the particular data category to be coded. The indices are found in Appendix B. Next, the type is coded $(1=$ comment, $2=$ labe 1 , and $3=$ numer $i c)$. Finally, any numeric 
data or comments are recorded. The proper columns to be used for coding are shown on page $\mathrm{C}-3$. As an example of this coding process consider the following.

Appendix $A$, page $A-7$, is the coding form format of a batch sorption experiment by Relyea. The coding tree form of these experimental results is shown on pages $\mathrm{C}-4$ to $\mathrm{C}-7$ of this appendix. A person could begin coding by associating the information under Reference on page A-7 with the proper box on B-2, Appendix B. Relyea corresponds to the box NAME. There are no further levels of categories below NAME; therefore, the box NAME is the most unique descriptor of Relyea. The identifying index would be $1,1,0,0$. The actual name Relyea would be a comment of type 1 . This data would be coded as found on line 1 , page $\mathrm{C}-4$.

The second piece of information on page A-7 is PNL. A level 3 category exactly describes PNL and has the index of $1,2,1,0$. This is a label and therefore a type 2. Line 2 page $\mathrm{C}-4$ shows the proper coding.

On page A-7 under GEOLOGIC MEDIA there is a total chemical composition given for $\mathrm{SiO}_{2}$. That composition is 67.5. Starting with the coding tree leve 11 category GEOLOGIC MEDIA on page B-4, one proceeds to the level 2 category TOTAL. The tree continues to levels 3 and 4 but on a separate page. TOTAL is on B-6. Proceeding to level 3 one can find a box for $\mathrm{SiO}_{2}$. The total chemical composition in $\mathrm{SiO}_{2}$ is broken down even more at level 4 . The 67.5 lies within the range specified by the $60-80$ box. Thus the index identifying $\mathrm{SiO}_{2}$ having a value of 67.5 is $3,3,1,5$. In the case of numeric data, the actual value 67.5 is also recorded on the same line, as shown on line 20 of page $C-4$.

These are three separate examples of how experimental data is recorded. The complete coding of all data on A-7 is shown on pages $C-4$ to $C-7$. This was accomplished by correlating each piece of data with the corresponding box or data category (Appendix $B$ ) best identifying it. 
$80-80$

REQUESTED BY

DATE

PAGE

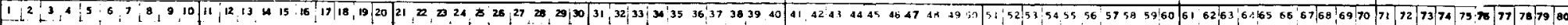

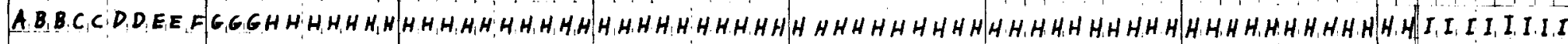

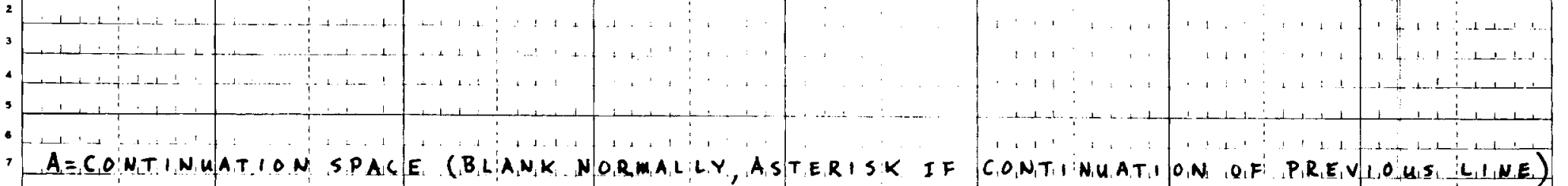

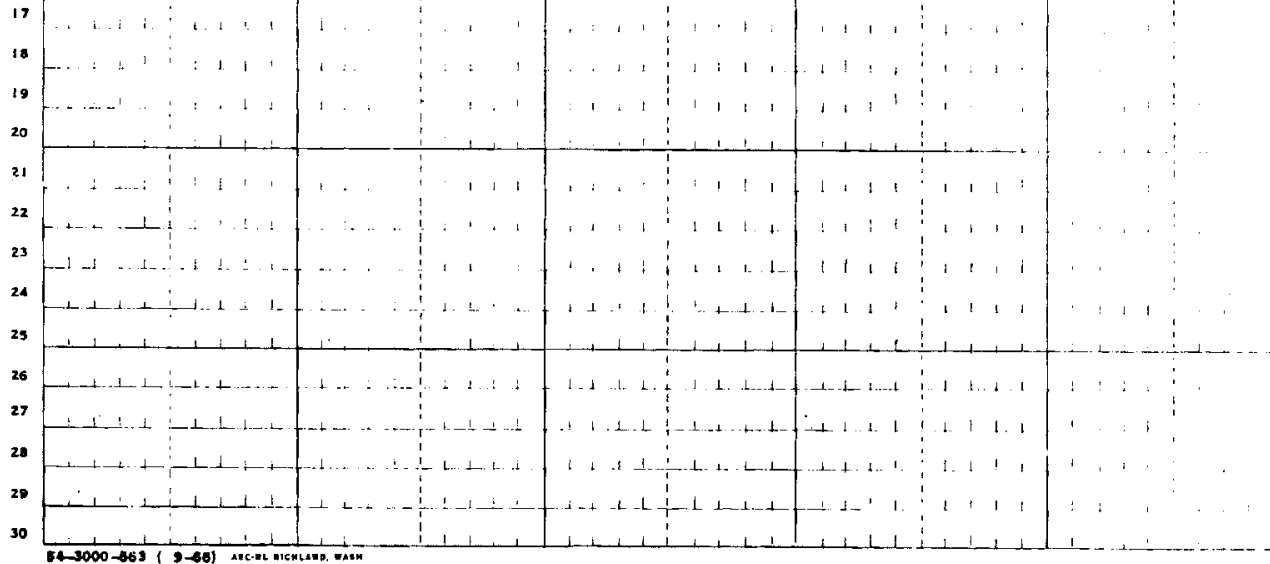

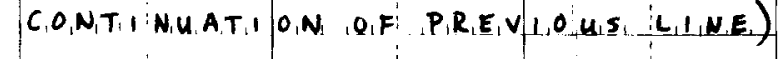
DATA CATLGORY' SPECAIFIER

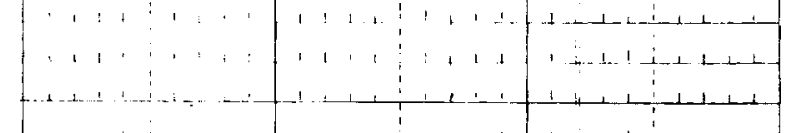

80 - 80 Sheet Data Input Format 


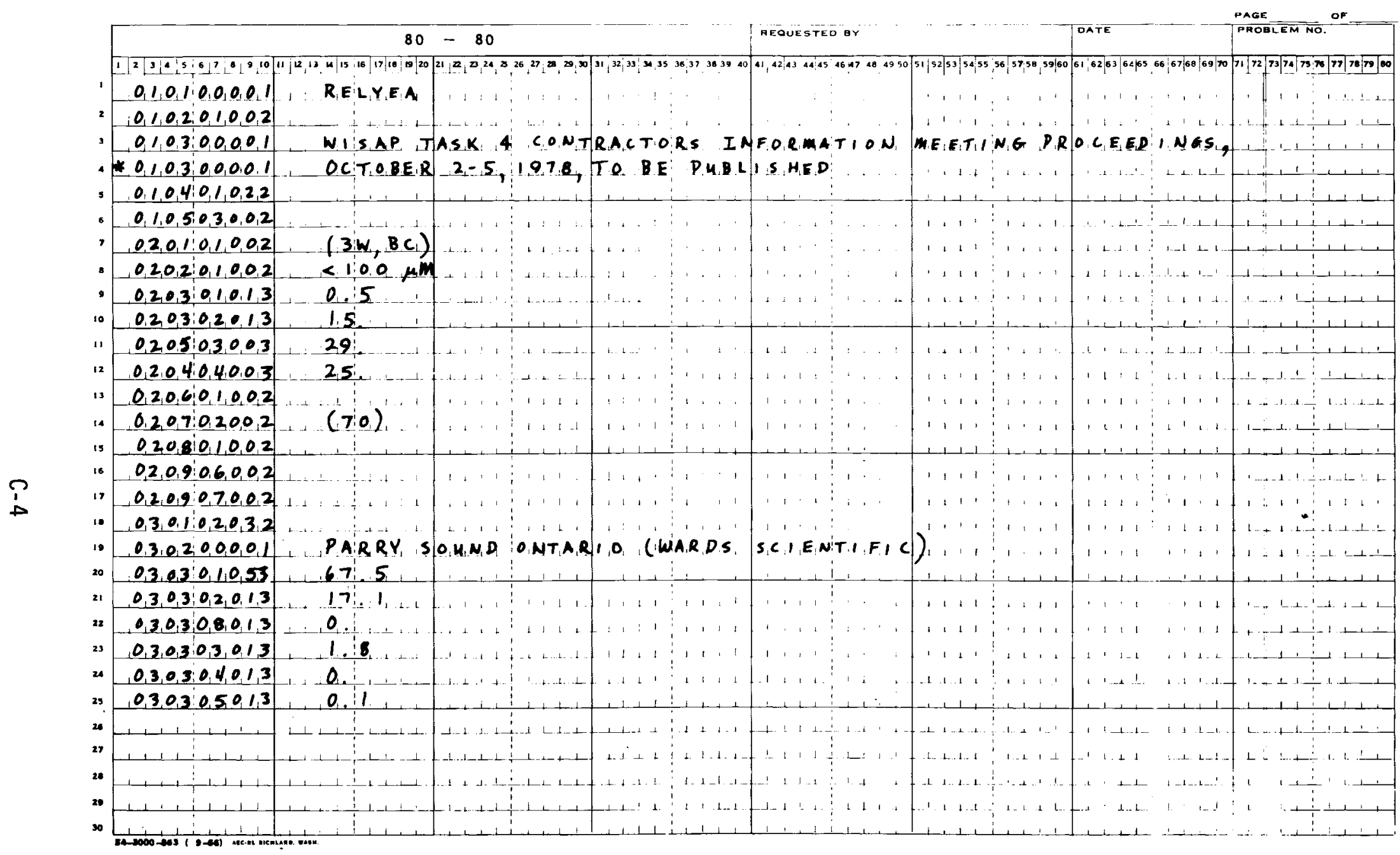

Sample Data Input 


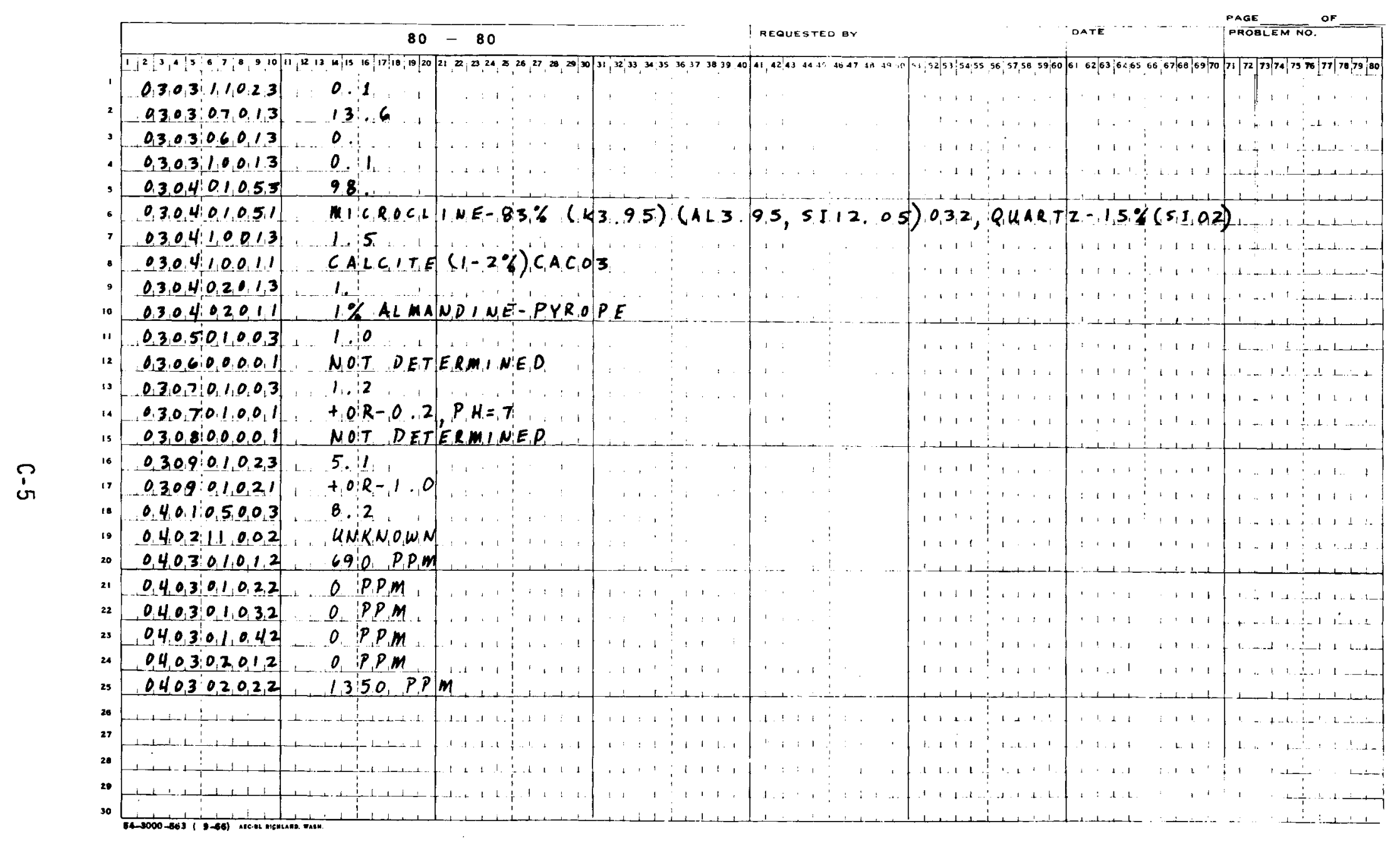

Samp le Data Input (contd) 


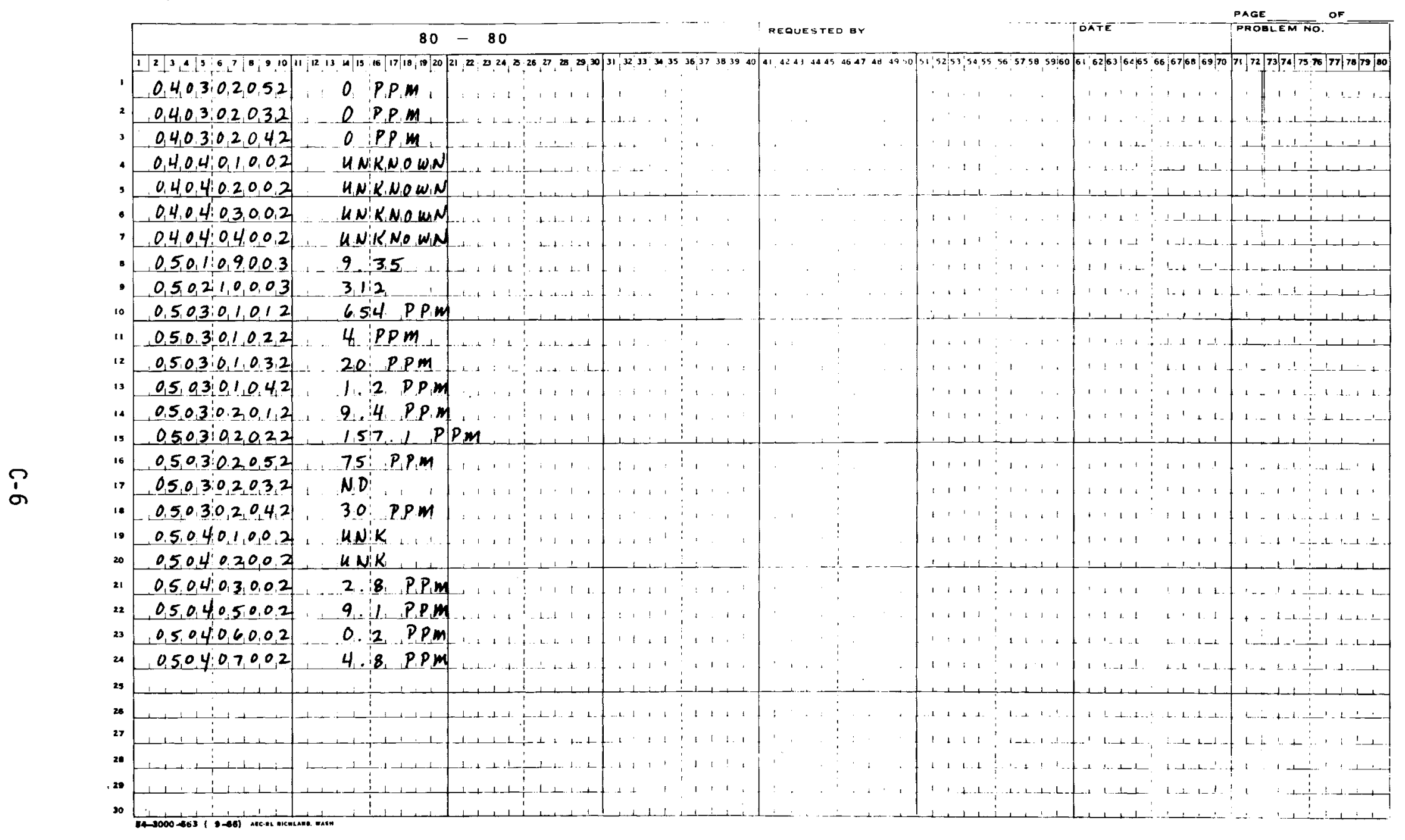

Sample Data Input (contd) 


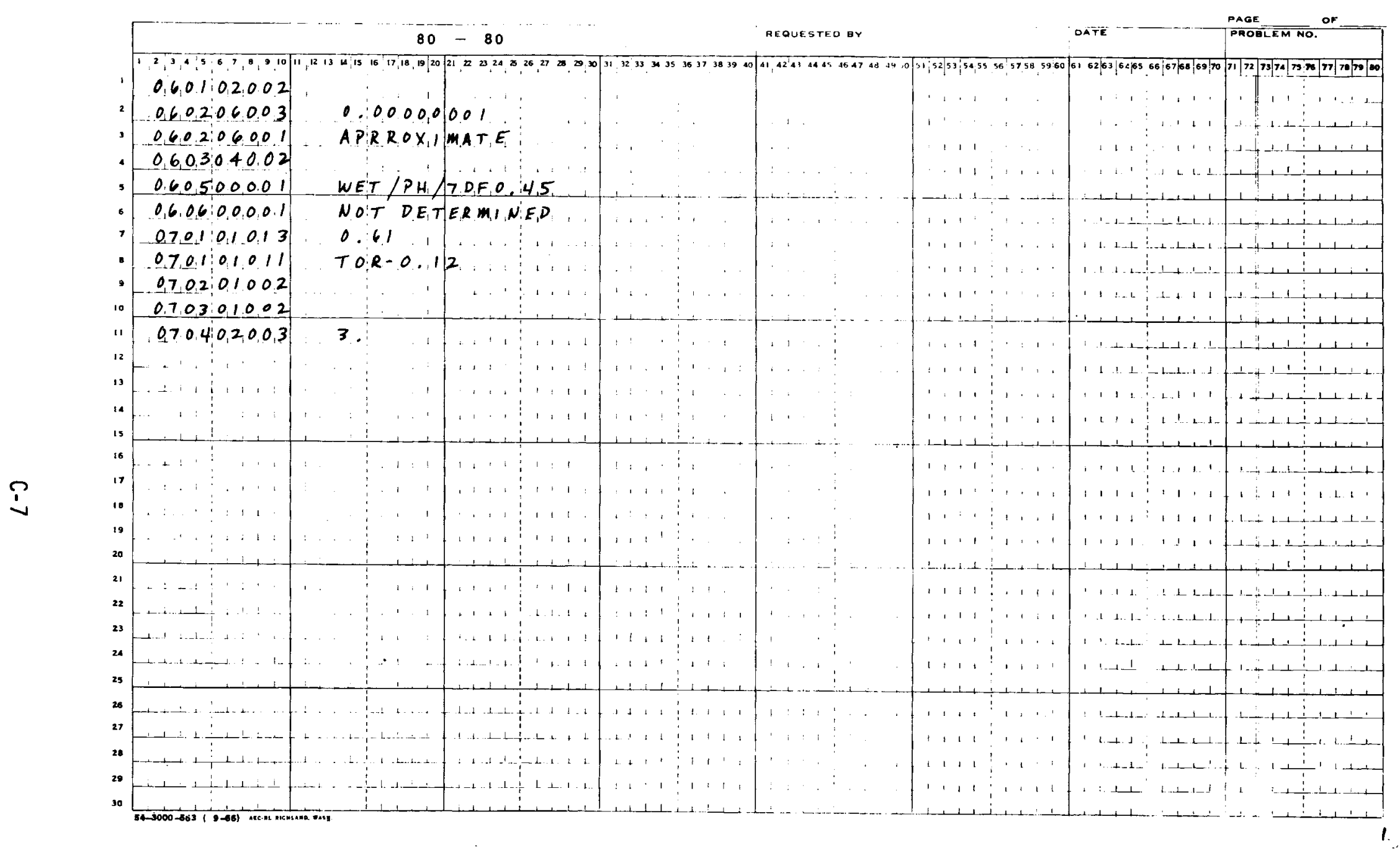

Sample Data Input (contd) 


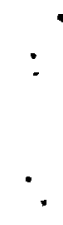


APPENDIX D

DATA QUALITY ASSURANCE PLAN 
The following is an outline of the quality assurance plan to be implemented for the sorption data base at the beginning of FY-1980. The procedures listed here in are designed to address two problems: computer code documentation and input data integrity.

\section{Computer Code Documentation Procedures}

At times judged to be important, all the SIRS input data and computer codes will be saved on magtape/disk for permanent storage. The UIC convention used to identify the progression in time of the data base will be:

$$
\begin{aligned}
& {[224,1]=\text { version } 1} \\
& {[224,2]=\text { version } 2 \text {, etc. }}
\end{aligned}
$$

A11 programs will be saved on the PDP-11/55 computer system. Necessary input files to regenerate the data base will be present on the same tape/disk. Dates and persons involved in saving the system will be clearly labeled on the tape/disk. Entry will be made in the SIRS Log Book. A file named:

\section{DI :HEADER. BLK}

will contain any pertinent comments concerning that version of the data base (i.e. changes in this version from the previous).

II. Input Data Integrity (steps of input)

1. Data are received from investigator and a copy made and filed (Appendix $C$ describes data input formats).

2. One copy of the coded forms are sent to Battelle's keypunching for processing. Cards should be verified by keypunching before their return.

3. The keypunched data is then run through a simple program to check for the presence of all necessary data categories and is processed to final form as needed by the main data base routines.

4. These can serve both as a simple summary and a future check on the main manipulative data base routines (interactive control programs). For example, the means and standard deviations of numeric data categories are computed. Next, the frequency distribution of each data category is computed. 
5. Finally, all input experimental data are printed out in a readable format (grouped by investigator). Two copies are made. One for PNL use and another to be separated by investigator. The latter copy is then sent to the contributing investigator for his/her verification.

6. At th is point, all data is stored properly for use. The data is then se lectively retrieved, processed, and compared with steps 3,4 , and 5 .

In conclusion, this QA procedure has established necessary backup copies and provided several methods of assuring data base integrity. Summaries of experimental data are available to data base users and contributors for cross reference and checking. All data base input activity should be summarized in the SIRS Log Book. The main entry items are:

- Number of experiments entered by each investigator

- The month and year of entry

- Person coding the data

- Person keypunching the data

- Person checking the data

- Any changes in coding procedure or method since last entry

- Date and location of any save files. 


\section{DISTRIBUTION}

No. of

Copies

\section{OFFSITE}
A. A. Churm
DOE Patent Division
9800 South Cass Avenue
Argonne, IL 60439

27 DOE Technical Information Center

John A. Apps

Lawrence Berkeley Laboratory

University of California

One Cyclotron Road

Building 90/1140C

Berkeley, CA 94720

Argonne National Laboratory

Reference Library

9800 South Cass Avenue

Argonne, IL 60439

Dr. Randy L. Bassett

Bureau of Economic Geology University of Texas

University Station, Box $X$

Austin, TX 78712

Batte 1le Memorial Institute

Office of Nuclear Waste

Iso iation

$505 \mathrm{King}$ Avenue

Columbus, $\mathrm{OH} 43201$

Attn: Bever ly Rawles

Gary Bea 11

Oak Rige National Laboratory

P.0. Box $X$

Oak Ridge, TN 37830

Larry Benson

Lawrence Berkeley Laboratory

University of California

One Cyclotron Road

Building 90/1140G

Berkeley, CA 94720
No. of

Copies

Ernest Bondietti

Environmental Sciences Division

Oak Ridge National Laboratory

Bldg. 1505

Oak Ridge, TN 37830

Brookhaven National Laboratory

Reference Section

Information Division

Upton, Long Is land, NY 11973

Douglas G. Brookins

Department of Geology

University of New Mexico

Albuquerque, NM 87131

Harry C. Burkholder

Office of Nuclear Waste Isolation

Battelle Memorial Institute

$505 \mathrm{King}$ Avenue

Columbus, $\mathrm{OH} \quad 43201$

Wayne A. Carbiener

Office of Nuclear Waste Isolation

Battelle Memorial Institute

$505 \mathrm{King}$ Avenue

Columbus, $\mathrm{OH} 43201$

Jess Cleve land

Denver Federal Center

U.S. Geological Survey

P.0. Box 25046

MS- 412

Lakewood, CO 80225

David G. Coles

Lawrence Livermore Laboratory

University of California

P.0. Box 808

MS-L233

Livermore, CA 94550 
No. of

Copies

Peter Co lumbo

Brookhaven National Laboratory Nuc lear Waste Management Group Upton, NY 11973

Carl R. Cooley

Department of Energy

Division of Waste Isolation

Washington, DC 20545

Jared Dav is

Nuc lear Regu latory Commission

Washington, DC 20555

Geoffrey Eichholz

Regent's Professor of Nuc lear Eng ineering

School of Nuclear Engineering

Georgia Institute of Technology

Atlanta, GA 30332

Environmental Protection Agency

Office of Radiation Progrmas

Technical Assessment Division AW559

Washington, DC 20460

Warren Eister

Department of Energy

Division of Waste Isolation

Washington, DC 20545

Bruce R. Erdal

LoS Alamos Scientific Laboratory

CNC- 11 , MS- 514

Los Alamos, NM 87545

Dan R. Fortney

Sandia Laboratories

Division 4512

Albuquerque, NM 87185

Sherman Fried

Argonne National Laboratory

9700 South Cass Avenue

Argonne, IL 60439
No. of

Copies

Colin A. Heath

DOE Division of Waste Isolation

Washington, DC 20545

William M. Hewitt

Office of Nuclear Waste

Isolation

Battelle Memorial Institute

$505 \mathrm{King}$ Avenue

Columbus, $\mathrm{OH} 43201$

Dana Isherwood

Lawrence Livermore Laboratory

P.0. Box 808

MS L-224

Livermore, CA 94550

Muzaffer Kehnemuyi

Office of Nuclear Waste

Isolation

Battelle Memorial Institute

$505 \mathrm{King}$ Avenue

Columbus, $\mathrm{OH} 43201$

John F. Kircher

Office of Nuclear Waste

Isolation

Battelle Memorial Institute

505 King Avenue

Columbus, $\mathrm{OH} 43201$

George A. Kolstad

DOE Division of Energy Research

Washington, DC 20545

Kurt Kraus

Oak Ridge National Laboratory

110 Ogontz Lane

Oak Rdge, TN 37830

Francine 0. Lawrence

Los Alamos Scientific Laboratory

MS- 514

Los Alamos, NM 87545 
No. of

Copies

Lawrence Berkeley Laboratory

Reference Library

University of California

Berkeley, CA 94720

Lawrence Livermore Laboratory

Reference Library

P.0. Box 808

Livermore, CA 94550

Stan E. Logan

Los Alamos Technical Associates, Inc.

P.0. Box 410

Los Alamos, NM 87544

Los Alamos Scient if ic Laboratory

Reference Library

P.0. Box 1663

Los Alamos, NM 87544

Richard W. Lynch

Manager, Department 4530

Sand ia Laboratories

P.0. Box 5800

Albuquerque, NM 87185

I an D. MacGregor

Department of Energy

Office of Basic Sciences

Mail Stop J-309

Washington, DC 20545

John T. McGinn is

Office of Nuclear Waste

I so lation

Batte lle Memorial Institute

505 King Avenue

Columbus, $\mathrm{OH} 43201$

I. Wende 11 Marine

E. I. du Pont de Nemours Co.

Savannah River Laboratory

Aiken, SC 29081
No. of

Copies

Robert E. Meyer

Oak Ridge National Laboratory

P.0. Box $X$

Oak Ridge, TN 37830

She ldon Meyers

DOE Office of Nuclear Waste Isolation

Washington, DC 20545

Martin A. Molecke

Nuc lear Waste Experimental

Programs

Division 4512

Sandia Laboratories

Albuquerque, NM 87185

Anthony Mucciardi

Adaptronics, Inc.

7700 01d Springhouse Road

McLean, VA 22101

Barry Naft

NUS Corporation

4 Research Place

Rockville, MD 20805

Jeff 0 . Neff

Department of Energy

Columbus Program Office

$505 \mathrm{King}$ Avenue

Columbus, $\mathrm{OH} 43201$

Ivars Neretnieks

University of California

Lawrence Berkeley Laboratory

Earth Sciences B1dg. 90

Berkeley, CA 94720

Neil A. Norman

Environmental Sciences

Department

Bechtel National Inc.

P.0. Box 3965

San Francisco, CA 94105 
No. of

Copies

Edward Norris

Los Alamos Scientific Laboratory

Group CNC-11 MS-514

P.0. Box 1663

Los Alamos, NM 87545

Oak Ridge National Laboratory

Central Research Library

Document Reference Section

Oak Ridge, TN 37830

George A. Parks

Standford University

Department of Applied Earth Sciences

Stanford, CA 94305

Gary Robb ins

U.S. Nuc lear Regulatory Commission

Division of Waste Management

Washington, DC 20555

Laura Santos

Nuclear Regulatory Commission

Office of Nuclear Research

Mai1 Stop 1130-SS

Washington, DC 20555

Savannah River Laboratory

Reference Library

Aiken, SC 29801

Barry E. Scheetz

Materials Research Laboratory

Pennsylvania State University

$\mathrm{Rm} 223$

University Park, PA 16802

Martin Seitz

Argonne National Laboratory

9700 South Cass Avenue

Argonne, IL 60439
No. of

Copies

Robert Silva

Lawrence Berkeley Laboratory

University of California

One Cyclotron Road

Building 70A/1160

Berkeley, CA 94720

Howard P. Stephens

Sandia Laboratories

P.0. Box 5800

Albuquerque, NM 87115

David B. Stewart

National Center 959

U.S. Geological Survey

Reston, VA 22092

Robert L. Watters

DOE Division of Biomedical and

Environmental Research

Washington, DC 20545

Allen Weiss

Brookhaven National Laboratory

Building 830

Upton, NY 11973

Ken Wilson

FUGRO, Inc.

3777 Long Beach Blvd.

Long Beach, CA 90807

Kurt Wolfsberg

Los Alamos Scientific Laboratory

CNC-11, MS 514

Los Alamos, NM 97545

H. Tom Yolken

National Bureau of Standards

Physics Building/B320

Washington, DC 20234 
No. of

Copies

FOREIGN

Dr. M. d'Alessandro

Division de las Chimie B. 46

Joint Research Center

Ispra

ITALY

Bert Allard

Cha Imers University of

Techno logy

Department of Nuc lear Chemistry 5-402 20 Goteburg

SWEDEN

Marc Bonnet

Service Geologique National

Bureau de Recherches Geologiques et Minieres

Avenue de Concyr

Or leans la Source (Loiret)

FRANCE

Bundesministerium fur Forschung und Technologie

Stressemannstrasse 2

D-5300 Bonn

F. R. of GERMANY

Les Dole

c/o Dr. Klaus Kuhn

Institut fur Tiefagerung

Wissenschaftiliche Abteilung

Berliner Strasse 2

3392 Clausthal - Zellerbeld

WEST GERMANY (FRG)

Ferruccio Gera

Radiation Protection and

Waste Management Division

Nuc lear Energy Agency/OECD

38 bou levard Suchet

75016 Paris

FRANCE
No. of

Copies

Ake Hultgren

Studsvik Energiteknik $A B$

Department of Waste Management

S-611 82 Nykoping

SWEDEN

2 INIS Clearinghouse

International Atomic Energy

Agency

P.0. Box 590

A-1011, Vienna

AUSTRIA

J. D. Mather

Environmental Pollution Section

Building 151

Harwe 11, Oxfordshire 0X11 ORA

UNITED KINGDOM

Ian Mckinley

Environmental Pollution Section

B1dg. 151

Harwe 11 Laboratory

Oxforshire 0x11 Ora

UNITED KINGDOM

Franz-Peter Oester le

PTB-Physikal isch-Techn ische Bundes anstalt

Bundesallee 100, Abteilung, SE

3300 Braunschweigh

GERMANY

Ruediger Scholz

c/o Bundesanstalt due

Geowissenschaften und

Rohstoffe

Stilleweg

3000 - Hannover-Buchholz

$F$. R. of GERMANY

Tjalle Vandergraff

Atomic Energy of Canada

Whiteshe 11 Nuclear Research

Establishment

Pinawa, Manitoba

CANADA ROE $1 L 0$ 
No. of

Copies

\section{ONSITE}

4 DOE Richland Operations Office

0. J. Elgert

H. E. Ransom

J. J. Schreiber

F. R. Standerfer

4 Rockwe 11 Hanford Operations

G. S. Barney

R. A. Deju

R. G. Johnston

R. C. Routson

52 Pacific Northwest Laboratory

L. L. Ames

D. J. Bradley

A. Brandstetter

W. J. Deutsch

F. H. Dove
No. of

Copies

D. W. Dragnich

M. A. Harwe 11

D. D. Hostetler (5)

J. H. Jarrett

M. R. Kreiter

K. M. Krupka

W. L. Kuhn

G. L. McVay

R. D. Nelson

H. M. Parker

A. M. Platt

D. Rai

J. F. Relyea

R. J. Serne

J. W. Shade

R. G. Strickert

R. A. Walter

R. E. Westerman

Technical Information Library (3)

Publishing Coordination RO (2)

Water and Land Resources Library (20) 